\title{
Posiciones internacionales del Brasil al nivel unilateral
}

\section{INTRODUCGIÓN}

Las relaciones entre la conducta de la política exterior brasileña y los asuntos internos ha llamado la atención de los académicos en esta área, como también el camino principal de la diplomacia brasileña en sus aspectos históricos ${ }^{1}$. Los objetivos de este trabajo son claros: trataremos de examinar aquellas posiciones que ha asumido el Brasil en el plano multilateral (de diplomacia parlamentaria). Al hacerlo así, intentaremos restringir nuestro examen, que no pretende ser exhaustivo, a sacar muestras de posiciones, actitudes y declaraciones básicas de delegaciones brasileñas en algunas organizaciones políticas internacionales, y, adicionalmente, examinaremos diversas áreas específicas de acción.

Sería difícil encontrar un punto de partida más conveniente para los objetivos de este trabajo que la Conferencia de San Francis. co y el desempeño del Brasil en la onU, seguido por una revisión de las posiciones más significativas del Brasil en la Asamblea General, el Consejo de Seguridad y la Conferencia de la ond sobre Comercio y Desarrollo (UNGTAD), como también en algunas de las principales conferencias internacionales efectuadas durante los últimos años bajo los auspicios de la onU (tales como Ia actual III Conferencia del Derecho del Mar, o la Conferencia sobre Medio

* Las notas al pie de página se publican en su idioma original.

${ }^{1}$ E. g., Helio Vianna, Historia Diplomatica do Brasil, São Paulo, Melhoramentos s/d., pp. 1-211; Jaime de Barros, A. Politica Exterior do Brasil (19301942), $2^{\text {a }}$ ed., Rio de Janeiro, Z. Valverde, 1943, pp. 1_308; Renato de Mendonça, Fistoria da Politica Exterior do Brasil, México, Instituto Panamericano de Geografia e Historia, 1945, pp. 1ss.; C. M. Delgado de Garvalho, Historia Diplomática do Brasil, São Paulo, Ed. Nacional, 1959, pp. 1-409; Hildebrando Accioly, O Reconhecimento da Independencia do Brasil, 2a ed., Rio de Janeiro, Imprensa Nacional, 1945, pp. 1-163; Helio Lobo, O Panamericanismo e o Brasil, São Paulo, Cia. Ed. Nacional, 1939, pp. 1-150; cf. also, e.g., Expedito Rezende, "A Evolução da Política Externa Brasileira", A Nova Ordem Mundial (I Painel de Assuntos Internacionais da Comissao de Relaçōes Exteriores da Camara dos Deputados), 2a ed., Brasilia, 1977, pp. 320-331; A. L. Cervo, "Os Primeiros Passos da Diplomacia Brasileira", 3 Relações Internacionais - Brasilia (1978) pp. 45 62. Cf. Bibliography infra, following footnotes. 
Ambiente, entre otras. Después de haber descrito las acciones del Brasil en diversas áreas de debates y reglamentaciones internacionales, este trabajo - bosquejará consideraciones relacionadas con el significado y el impacto del fenómeno del multilateralismo en las relaciones internacionales contemporáneas.

\section{Partigipación del Brasil en las Nactones Unidas con ocasión de la Conferencia de SAN Francisco (1945)}

Brasil estuvo entre los miembros fundadores de la Liga de las Naciones, precursora de las Naciones Unidas, y de la misma oNU, ha biendo sido participante en la Conferencia de San Francisco. El Informe de la Delegación del Brasil a la Conferencia indica que durante la redacción de la Garta de Naciones Unidas, Brasil formó parte del "cohesivo" bloque latinoamericano en la Conferencia de San Francisco (25 de abril a 26 de junio de 1945) ${ }^{2}$. Las tareas de la Conferencia fueron distribuidas entre cuatro comisiones. La Primera Comisión (Acuerdos Generales), compuesta por dos Comités; là Segunda Comisión (Asamblea General, con cuatro Comités), la Tercera Comisión (Consejo de Seguridad), también con cuatro Comités y la Cuarta Comisión (Organización Judicial), compuesta por dos Comités. Brasil estuvo representado en las cuatro comisiones y en todos los Comités ${ }^{3}$.

Como es sabido, la principal victoria del bloque latinoamericano $^{4}$ (que juntos sumaron diecinueve de los cincuenta y un estados miembros fundadores de la oNv) fue la inserción del artículo 51 en la Carta de la oNv5, reconociendo el principio de la defensa propia individual o colectiva (una importante excepción a los poderes del Consejo de Seguridad en lo referente a salvaguardar la paz y seguridad internacionales) ${ }^{\circ}$. El Gapítulo virl de la Garta de la oNU, que regula los acuerdos regionales, "fue incluido en su forma final por causa de la influencia de los países latinoamericanos en la Conferencia de San Francisco, como un medio para dar un status adecuado al Sistema Interamericano en el nuevo orden internacional"'?

Relatorio đa Delegação do Biasil a Conferéncia das Nações Unidas para a Organização Internacional $(1945)$, p. 6 (orginally typewritten, and now part of the archives of the Federal Supreme Court in Brasilia).

${ }^{8} \mathrm{Cf}$. ibid, pp. 2-3.

Which was followed in 1960 by the numerous-membered Afro-Asiatic block in the U.N.

Referred to in article 3 (1) of the Inter-American Treaty for Reciprocal Assistance (Rio de Janeiro, 1947) ; regarding articles 5I (individual or collective self-defense) and 53 (regional security) in the U.N. Charter, cf., e.g. E. Ji. ménez de Arechaga, Derecho Constitucional de las Naciones Unidas, Madrid, Esc. Func. Internacionales, 1958, pp. 397-425.

'Cf.; regarding Relatorio da Delegação do Brasil, cit. supra No 2; p. 9 .

${ }^{2}$ R. E. Saraiva Guerreiro, "Conceito e Funcionamento dos Organismos Inter: nacionais Mundiais e Regionais", 17 Revista Brasileira de Polltica Trateriacional (1974) No 65/68, p. 8 . 
El Informe de là Delegación Brasileña enfatiza, entre otros puntos muy debatidos en la Conferencia de San Francisco, Io siguiente: composición y operación del Consejo de Seguridad (particularmente en lo referente a los poderes de veto), la creación del Consejo Económico y Social (en reconocimiento de la "interdependencia económica de las naciones"), composición y jurisdicción de la Corte Internacional de Justicia, el status jurídico de la oNu y la interpretación de la Carta y de los poderes atribuidos a sus diversos órganos 8 .

A pesar del éxito que obtuvo el Brasil al insertar la cláusula de la defensa legítima en la Carta (Artículo 51), no consiguió que se aprobaran otras propuestas propias o apoyadas por el país. Por ejemplo, Ias delegaciones del Brasil, Checoslovaquia, Ecuador, Grecia, México, Perú, Turquía y Venezuela efectuaron una serie de propuestas por las cuales habría sido responsabilidad de la Corte Internacional de Justicia certificar, en casos controvertidos, el dominio reservado a los Estados (Artículo 2 (7) de la Carta de la ONU). Estas propuestas fueron sobrepasadas por la fórmula adoptada por el Comité rv/2 de la Conferencia de San Francisco, colocando la responsabilidad en cada órgano de la onU para interpretar, en el ejercicio diario de sus operaciones, aquellas partes de la Carta de la ONU aplicables a sus funciones particulares?. Por lo tanto, la Corte (el órgano judicial de la ONU), como también, por ejemplo, la Asamblea General o el Consejo de Seguridad (órganos políticos de la ONU), tendrían poderes interpretativos.

Inclusive durante la fase de trabajo de la Carta de la onv, Brasil propuso una enmienda al artículo $2(4)$, para que se incluyera la coerción económica bajo la prohibición general del uso o amenaza de fuerza en las relaciones internacionales sancionadas en esa disposición ${ }^{10}$. Pero la coerción fue rechazada por presión de la delegación norteamericana ${ }^{11}$. El punto de vista que prevaleció fue corroborado recientemente por la adopción de la Definición de Agresión en 1974, que fue redactada por un Comité Especial de la oNU y que también excluye el concepto de agresión económica de la definición a la que se llegó después de varios años de trabajo y negociaciones ${ }^{12}$. Una tesis reciente sobre el tema muestra inter alia

${ }^{8}$ Relatorio ..., ibid, pp. 8, 11-13 (Brazil's position on the veto in the Security Council); 15; 4th Commission, Ist Committee, pp. 3-6; and 4th Commission, 2nd Committee, pp. 1-3.

${ }^{\circ} \mathrm{A}$. A. Cançado Trindade, "The Domestic Jurisdiction of States in the Practice of the United Nations and Regional Organisations", 25 International and Comparative Law Quarterly (1976) pp. 717-719. And cf. Relatorio..., cit. supra No 2, 4th Commission, 2nd Committee, p. 2.

${ }^{10} \mathrm{Cf}$. 6 United Nations Conference on International Organization (1945)

p. 559 .

"Cf. ibid:, pp. 335 and 459 .

${ }^{12} \mathrm{Cf}$. text in $\mathrm{ONU}$, document $\mathrm{A} / 9890$, December 6, 1974, pp. 1-7. 
que si bien en la Conferencia de San Francisco el cargo (en vano) en contra de la agresión económica fue el resultado de la iniciativa de la delegación brasileña, más recientemente durante los largos travaux preparatoires de la Definición de Agresión (supra), fue el representante peruano quien sostuvo la causa, abogando que la "autodefensa se justifica no sólo contra un ataque armado sino también contra todos los actos de agresión"13. Por tanto, el Brasil difirió de la posición original adoptada en la 'Conferencia de San Francisco (supra), al reconocer la "dificultad que existe para adoptar una definición de agresión, que ciertamente no puede incluir todas sus formas (de agresiones)"14.

En efecto, el principio de no intervención fue el objeto de atención especial durante la Gonferencia de San Francisco; una de las enmiendas presentadas por la delegación brasileña se ıefería al "principio de no intervención en asuntos internos y externos de cualquier país, ya sancionado en las Convenciones de Montevideo, el Protocolo de Buenos Aires y la Declaración de Lima"15. Como bien se sabe, el principio está bien fundamentado en la práctica por los estados latinoamericanos, por haber sido sancionado en las conocidas Conferencias Interamericanas. Esas Conferencias han tenido tal importancia en el desarrollo del sistema interamericano que hoy en día muchos, tales como Sepúlveda, las consideran a ellas y a los preceptos de ellas como una fuente par excellence de aqueIlo que es conocido como el Derecho Internacional Americano' ${ }^{16}$. Sin duda, las Conferencias ${ }^{17}$ contribuyeron a la cristalización de ciertos principios prevalecientes en las relaciones interamericanas, tales como la igualdad y autodeterminación de los estados, la norma de no intervención, el asilo diplomático, la extensión dẹ aguạs territoriales, la cláusula Calvo, la doctrina Drago, la doctrina Calvo sobre la igualdad entre nacionales y extranjeros (en lo refexente a derechos civiles), la doctrina Jefferson (en lo que se refiere al reconocimiento de los gobiernos) y la doctrina Stimson sobre el no reconocimiento de las adquisiciones territoriales por fuerza ${ }^{18}$.

${ }^{23} \mathrm{Ch}$. R. Oleszycki, Economic Aggression and Self-Defense (Cambridge Diploma Thesis), University of Cambridge, 1975, pp. 28-29 and cf. p. 26 (internal circulation, unpublished).

${ }^{11}$ Even so, the Brazilian delegation admitted to the need to take into account "economic, financial, or political pressure"; Relatorio do Ministerio das Relações Exteriores, 1969, M. R. E., 1973, p. 83. And cf. also in this regard, M. R. E., Documentos de Politica Externa, vol. vr, 1972, pp. 234-235.

${ }^{1 \sigma}$ Relatorio da Delegaşäo do Brasil..., op. cit. supra No 2, p. 14.

${ }^{18} \mathrm{C}$. Sepúlveda, Las Fuentes del Derecho Internacional Americano, México, Ed. Purrúa, 1975, p. 95.

${ }^{17} \mathrm{Cf}$. Conferencias Internacionales Americanas, vols. I and II (supplements, Washington, Carnegie Endowment for International Peace, 1943 and 1956, respectively.

${ }^{18}$ C. Sepúlveda, op. cit. supra No 16, pp. 77.84 and 95-103. 
En la vr. Conferencia de La Habana en 1928, surgió particularmente el principio del derecho de no intervención, que fue clarificado después en la Conferencia de Montevideo de 1933 y que evolucionó hasta casi lilegar a su forma final en la Conferencia de Buenos Aires de 1936. Finalmente fue adoptado en la Carta de la oEA. en 1948 (Artículo 18 de las reformas de Buenos Aires, 1967) y en la Resolución 2131 (xx) de 1965 en la Asamblea General de la ONU19. La doctrina Drago (prohibiendo el uso de la fuerza para recolectar deudas contractuales de un estado) contribuyó en forma decisiva hacia la adopción del principio general que prohibía el uso de la fuerza en las relaciones internacionales en el Artículo 2 (4) de la Carta de la onU'20.

En la Opinión Gonsultiva de enero de 1962 sobre la "Contribu" ción del Continente Americano a los Principios de la Ley Internacional que gobierna Ia Responsabilidad del Estado", el Comité Jurídico Interamericano de la Organización de Estados Americanos (OEA), inter alia, recapituló todos los esfuerzos de los estados del continente para cristalizar. el principio de no intervención a través de las Conferencias Interamericanas, protocolos, provisiones de tratados y declaraciones. El documento consideró el principio de no intervención como fundamental al sistema interamericano, siendo hoy "contractualmente obligatorio en veintiuna república americanas"21. (Es apropiado hacer notar que en esta ocasión se tomó bien el que el Brasil restringiera su posición, dado el alcance de la cláusula Calvo, que no fue endosada ni en la práctica ni en la doctrina por el Brasil) ${ }^{22}$.

Desde el principio, Brasil defendió el principio de no intervención y lo afirmó en el trabajo de la Conferencia de San Francisco (supra); y su posición fue confirmada recientemente en la quinceáva Reunión Consultiva de Ministros de Relaciones Exteriores de los países miembros de la ofa (Quito, noviembre de 1974). En esa ocasión, el entonces Ministro de Relaciones Exteriores Azeredo da Silveira declaró que "para Brasil, el principio de no intervención en los asuntos internos de otros estados es el fundamento de las buemas relaciones internacionales. Es aún más fundamental entre países del continente"23.

10Ibid., p. 100. On the subject, cf. the studies of A. V. W. Thomas and A. J. Thomas, Yr., Non-Intervention - The Law and Its Import in the Americas, Dallas, Southern Methodist Univ. Press, 1956, pp. 3-416; and I. Fabela, Interventions, Paris, Pedone, 1961, pp. 67-212 (on OAS practices).

2 ... Falta. nota en el original.

"Comité Jurídico Interamericano, R'ecomendaciones e Informes - Documentos Oficiales, vol. vIr, Rín de Janeiro,. 1964, p. 188, and cf. pp. 187-193.

C.f. ibid, .pp, 216-271.

${ }^{2 M . R . E ., ~ R e s e n h a ~ d e ~ P o l i t i c a ~ E x t e r i o r ~ d o ~ B r a s i l, ~ № ~ 3, ~ O c t o b e r-D e c e m b e r ~}$ 1974, p. 25. 
En 1970, una significativa declaración del entonces Ministro de Relaciones Exteriores, Mario Gibson Barbosa, enfatizó que la mültilateralización de los contactos internacionales ${ }^{24}$, representaba una tendencia irreversible y que ellos constituyeron el factor clave y el mecanismo diplomático central en su forma de relación multilateral, y esta fue la razón para la activa participación del Brasil en virtualmente todos los consejos y agencias especializadas de las $\mathrm{Na}$ ciones Unidas ${ }^{25}$. Durante la administración anterior, el Ministro Magalhaes Pinto, en el plenario de la únctad II (Nueva Delhi, febrero 5 de 1965), había condenado las políticas monopólicas de los superpoderes (p. ej., impidiendo que los países en desarrollo adquiriesen y perfeccionasen su tecnología autónoma) ${ }^{26}$ y anteriormente habia caracterizado su posición como ministro tanto en la ONU como en la oEA, por el. énfasis que el Brasil dio a la cooperación en el desarrollo como una forma de asegurar la paz internacional y la seguridad ${ }^{27}$. A principios de los años 70 parecía no haber duda, como lo demuestran los archivos de Itamaraty, que en el corazón de las Naciones Unidas, los aliados más constantes del Brasil habían sido, cosa no sorprendente, los poderes pequeños y medianos ${ }^{28}$.

Sin embargo, la formación de bloques de presión y negociación en la onU es mutable y se ha adoptado y modificado como la función del momento histórico, el grado de desarrollo buscado individualmente por los estados y la naturaleza de los intereses en juego (cf. p. ej. los bloques de negociación en la actual Tercera Conferencia del Derecho del Mar (1974-1980), Brasil parecía estar consciente de ello, incluso cuando dirigió el Grupo de los 77 en la Segunda UNGTAD (cf. infra). Así, sólo un año y medio después de su discurso en Nueva Delhi (1968), el Canciller Magalhaes Pinto denunció a los superpoderes como "el gran poder de coerción" en las relaciones internacionales: "en mayor o menor grado, todas las unidades más fuertes pueden ejercitar una medida de coerción en relación con aquellas unidades más débiles clentro de su círculo de influencia"29.

Pero esta vez el Ministro subrayó que si los intereses del Brasil no igualaban a aquellos de los países desarrollados, ni necesaria: mente se identificaban con aquelios de los países subdesarrollados; era necesario negociar con los países desarrollados y acercarse a

II In this regard, and on the foreign policy of the Latin American countries. cf. E. S. Milenky, "Latin America's Multilateral. Diplomacy", 53 Intemational Affairs (1977), pp. 73.96 .

"M.R.E., Documentos de Politica Externa, vol. rv, 1969-1970, p. 190.

oNM.R.E., Documentos de Politica Externa, vol. II, 1967-1968, p. 56.

2T.R.E., Documentos de Politica Externa, vol. x; 1967, p. 82.

${ }^{28}$ M.R.E., Documentos de Politica Externa, vol. Iv. 1969:1970, p. 192.

ouosé Magalhaes Pinto, "A Política Externa do Brasil", 25 Bolatim da: Saciedade Brasileira de Direito Internacional (1969) p: 65:. 
aquellos países relativamente desarrollados comparados con Brasilio. El Canciller brasileño advirtió que "los países subdesarrollados - unidos políticamente en sus reclamos, pero enfrentando problemas similares, son conducidos por el camino de la competencia en sus intercambios internacionales. De esta manera, surgió un conflicto entre los objetivos del Brasil y aquellos de los países subdesarollados. Al respecto, existe un conflicto entre el interés en acelerar el crecimiento interno y las fórmulas de desarrollo presentadas por los países industrializados" 31 .

Ya en la Conferencia de San Francisco de 1945, se previó la necesidad de, eventualmente, desarrollar una categoría "intermedia" para los estados miembros de la ONU, compuesta de países tales como Canadá, Australia, Brasil y otros. Esta categoría estaría a medio camino entre los grandes poderes y los pequeños estados. Con el paso de los años, dentro de la UNCTAD surgió algo similar a la posición del Brasil, tal vez con un efecto mayor. Si bien Brasil había llenado la presidencia del Grupo de los 77 en 1968, en la IV UNCTAD (Nairobi, 1976), comenzó a ponderar - como veremos más adelante- el futuro desarrollo de un nuevo bloque, intermedio entre el Grupo de los 77 y el Grupo B de los países industrializados. Este incluiría países tales como Brasil, Argentina, Israel y Singapur, y tal vez Venezuela y Kuwaits2 (cF. infra). Para seguir 'más de cerca el desempeño del Brasil en la ONU, es útil revisar, por ejemplo, las posiciones de los representantes del Brasil en la Asamblea General y el Consejo de Seguridad (particularmente durante las dos últimas décadas).

\section{Posiciones del Brasil en la Asamblea General DE LAS NAGIONES UNIDAS}

Ya durante los primeros años de la onv, la delegación brasileña dio a conocer su presencia en el trabajo de la Asamblea General. Por ejemplo, en 1952 Brasil presentó exitosamente ante la Asamblea, a pesar de las objeciones de la delegación soviética, el caso para la conclusión del tratado de paz para restaurar la soberanía total de Austria. Además, Brasil tomó parte en los debates de la Asamblea con respecto a los asuntos de Túnez y Marruecos (1952) y la reso-

\footnotetext{
${ }^{80} \mathrm{CF}$. ibid., p. 71; He further added that economic development was the " $i$ ternal responsibility of each country", and should be undertaken with its orw resources and not based "on simple external indebtedness" or the "leftovers of someone else's progress" (ibid., p. 76).

sIbid., pp. 69-70.

${ }^{3}$ Ch. R. Evans, "UNCTAD: Should Group B Remain Group B?", 12 Journal of World Trade Law (1978) pp. 241-244. On the "new" Brazilian position in its relations with other developing countries, cf. R. Roett and W. Perry, "Recent Trends in Brazilian Foreign Policy", The World Today - London (August 1977) p. 304, and cf. pp. 295-304.
} 
lución de la paz de Corea (1953) ${ }^{33}$. En 1952, la cabeza de la delegación brasileña (Augusto Frederico Schmidt) trajo el tema de la "lucha contra el subdesarrollo" ante la Asamblea ${ }^{34}$.

Con la emergencia de quince estadòs africanos y Chipre en la escena internacional, dominó en la Xv Asamblea General (1960) el debate sobre la aplicación del principio de la autodeterminación de las personas. Brasil defendió este principio y se mostró favorable hacia el borrador de la Declaración sobre la Concesión de Independencia a países y personas coloniales ${ }^{35}$, pero simultáneamente, y paradojalmente, se alió con Portugai al endosar la posición de Portugal de que las colonias portuguesas "constituyen provincias de un estado unido" 36 .

Se consideró, de acuerdo con el creciente número de estados miembros de la ONU, un número igual de puestos adicionales en el Consejo de Seguridad, en el Consejo Económico y Social (ECOSOC) y en la Corte Internacional de Justicia, un cambio que Brasil favorecio $^{\mathbf{a} T}$.

El año siguiente, al seguir una "línea de independencia" en su política exterior, Brasil hizo suyas las causas del desarme y detención de pruebas nucleares (Brasil había sido elegido unánimemen-

"Geraldo Eulalio do Nascimento e Silva, Sistema Mundial de Segurança CoLetiva: a Posição do Brasil na onv, Ministerio das Relações Exteriores/Instituto Rio Branco, 1955 , pp. 29-32; similarly, in the Security Council Brazil participated in debates on Guatemala's complaint against Honduras and Nicaragua (1954); cf. ibid., pp. 33-35.

${ }^{3}$ And he makes reference to the Pan-American Operation (of Kubitschekj; statement reproduced in: Ministerio das Relações Exteriores, O Brasil na XIY Assembleia Geral das Nações Unidas em Nova York, 1959, p. 11, and cf. pp. 8-12. On the Pan-American Operation, cf.: Ministerio das Relaçōes Exteriores, Artigos e Entrevistas sobre a Operação Pan-American, M.R.E.jSec. Publ., 1959, pp. 3-77; Licurgo Costa, Uma Nova Politica para as Américas - Doutrina Kubitschek $e$ o.P.A., São Paulo, Livr. Martins Ed., 1960, pp. 1-522; Celso A. de Souza e Silva, "Operação Pan-Americana: Antecedentes e Pexspectivas", 9 Revista Brasileira de Politica Internacional (1960), pp. 41-59; J. O. de Meira Penna, op. cit. infra No 73, pp. 101-106.

${ }^{3}$ On this point, cf. A. A. Cançado Trindade, "Desenvolvimentos Recentes no Direito Internacional Contemporáneo", 24 Revista da Faculdade de Direito da UFMG (1976), pp. 146-154 (parte 3: "Descolonização e Cristalização do Direito de Autodeterminação dos Povos"); A. A. Cançado Trindade "Direito e Relações Internacionais; Resenha Bibliografica Seletiva", Relações Internacionais Brasilia (1980), pp. S4-86 (parte III: "O Direito de Autodeterminação dos Po$\left.\operatorname{vos}^{\prime \prime}\right)$.

saM.R.E. Relatorio do Ministerio das Relaşôes Exteriores - 1960, pp. 14-15.

37 Ibid., p. 15; plans for execution of the Pan-American Operation, disarmament and the principle of non-intervention were other issues Brazil debated; $\mathrm{cF}$. ibid., pp. 13 and 16. - The Brazilian representative (Horacio Lafer) also supported the inclusion of an item on racial discrimination in the Assembly agenda; in General Assembly Official Records (henceforth cited as G.A.O.R), 15th Session, Plenary Neetings, 1960, p. 45 §16; and cf. also M.R.E., Gestao do Ministro Lafer na Pasta das Relaçốes Exteriores, 1961, Anexo 7, pp. 107.112. 
te por la Asamblea General al Comité de Desarme, compuesto por dieciocho países) y nuevamente estaba al mismo lado que la mayoría de los países afroasiáticos en votos sobre asuntos coloniales (si bien Brasil se había abstenido de votar la autodeterminación de Algeria). Así, Brasil condenó las políticas de apartheid en Sudáfrica y favoreció el uso de la presión directa sobre el gobierno sudafricano para obligarlo a abandonar tales políticas ${ }^{38}$.

En 1962, apareció de nuevo el desarme en el discurso del representante del Brasil. (Melo Franco) ante la Asamblea General. Aún más, él auspició la revisión de la Carta de la onu, que había sido escrita durante la "Guerra Fría" y "antes de la era atómica y espacial". Brasil nuevamente abogó por la prohibición de todas las pxuebas nucleares, como también por el establecimiento de "zonas desnuclearizadas" en algunas regiones tales como América Latina, y el uso pacífico del espacio exterior ${ }^{39}$. Brasil continuó insistiendo en el principio de la autodeterminación de las personas, destacando las resoluciones de la Asamblea General 1.514 (xv), 1.541 (xv) y $1.654(\mathrm{xVI})$ y en el principio de la no intervención ${ }^{40}$.

Gon la reciente crisis de los misiles cubanos ${ }^{41}$, en 1962, la delegación brasileña expresó que el problema del desarme era "el tema rás urgente e importante entre todos los temas que ocupaban la atención de la Asamblea General" y comenzó a tomar forma el proyecto de desnuclearización de América Latina, considerada necesaria por Brasil. La delegación brasileña al Comité de Desarme (compuesta de dieciocho naciones) insistió en dar por terminadas las pruebas nucleares ${ }^{42}$. Además, Brasil nuevamente condenó el apartheid sudafricano y definió su posición anticolonial y la aprobación al derecho y la autodeterminación, votando junto con las mayorías afroasiáticas y latinoamericanas, excepto por abstencio-

${ }^{25}$ During the xvi U.N. General Assembly, Brazilian Ambassador, Gilberto Amado, was elected by 96 out of 101 voting countries to sit on the U.N. Commission on International Law, of which he had been a founding member. Cf. "Atividades da Delegação do Brasil a xvı Sessao da Assembleia Geral das Nações Unidas", 17 Boletim da Sociedade Brasileira de Direito Internacional (1961) No 33/34, pp. 73-77 and 81-84.

${ }^{39}$ G.A.O.R., 17éme. Session, Seances Plenieres, 1962, pp. $18-19$ §12-27.

${ }^{40}$ Tbid., pp. 20-21, §28 and 35 .

${ }^{" 1}$ Cf., regarding, e.g., Abram Chayes, The Cuban Missile Crisis, Oxford, University Press, 1974, pp. 1-106; Luis Medina Pena, El Sistema Biplor en Tensión (La Crisis de Octubre de 1962), México, D. F., El Colegio de México, 1971, pp. 1.110 .

*'s:'Sumario das Atividades da Delegação do Brasil a xvrr Sessao da Assembleia Geral", 19 Boletim da Sociedade Brasileira de Direito Intermacional (1963) No 37-38, pp. 122-124. Also, Australia and New Zealand recently charged France before the International Court of Justice regarding French nuclear tests in the South Pacific, but the Court's decision on the case was inconclusive and reluctant, and in fact, quite unsatisfactory; cf. ICJ. Reports (1974) pp. 253-274, and, for. a study, cf. Pierre Lellouche, "The Nuclear Tests Cases: Judicial Silence v. Atomic. Blasts", 16 Harvard International Law Journal (1975) pp. 614-637. 
nes en asuntos pertinentes a territorios bajo administración pórtuguesa ${ }^{43}$.

Vale la pena recordar que a principios, de los años 70 , si bien Brasil permaneció fiel al sistema interamericano, en el planó global hizo un esfuerzo de una "admisión de neutralismo" para mantener una posición de "tercera fuerza"; esto es, "no adherirse estrictamente a ninguno de los dos bloques de poderes"4x. De este modó, se comprometió en políticas más activas en relación con el mundo subdesarrollado, en un esfuerzo para defender su neutralidad en la periferia de una confrontación Este-Oeste. Ciertamente esta pósición estuvo también influida por la situación internacional genèral. Como observaba un analista del período, "la posibilidad de una guerra nuclear, limitada o ilimitada, deja a las naciones periféricas instintivamente convencidas de que la mejor posición era la neutral"45.

Incluso en la XvII Asamblea General (1962), la delegación brasileña dio la bienvenida a cada uno de los seis nuevos esțados cuya admisión fue aprobada unánimemente por la Asamblea (Algerià, Burundi; Jamaica, Trinidad y Tobago, Ruanda y Uganda) ${ }^{46}$. Habiendo transcurrido casi una década; la Carta Internácional de Justicia, en su loada Opinión Consultiva del 21 de junio de 197i, declaró inter alia que la continuada presencia de Sudáfrica en Námibia era ilegal, y afirmó que los estados miembros de la onU ténían la obligación de reconocer la ilegalidad de esta presencia ${ }^{47}$. Brasil defendió la decisión de la Gorte condenando la presencia sudafricana en Africa Sudoccidental ${ }^{48}$ y en la $\operatorname{xxxi}$ Asamblea General de 1976 defendió la autodeterminación de Namibia, como también la transferencia de poder de Rodesia a la mayoría negra ${ }^{49}$. Dos

43"Sumario das Atividades...", cit. supra NQ 42, pp. 130 and 125-126. Brazil supported the statement of the International Court of Justice in the case of Certain U.N. Expendilures (1962), related to peace and security operation costs; cf. ibid., pp. 127-128.

"V. Reisky de Dubnic, "A Polftica Externa do Brasil no Governo Janio Qua.. dros", 3 Sintese Politica, Económica, Social (1961) No 9, pp. 76-77.

stibid., p. 80 and cf. pp. 81 and 86 . - One notes, however, that on his visit to the United States in 1962, then-Presidente Joäo Goulart addessed the U.s. Congress affirming that "Brazil was an independent but not neutral country", (expressing his opposition to the Cuban regime of Fidel Castro); $\dot{T}$. E. Skidmore, Brasil: de Getulio Vargas a Castelo Branco (1930_1964), 4a ed., Rio de. Janeiro, Paz e Terra, 1975, pp. 265-266.

${ }^{*} \mathrm{Cl}$. op. cit. supra № 43, p. 124.

"Case of the Consequencias Legais para os Estados da Presença Continuada da Africa do Sul na Namibia a Despeito da Resolução 276 (1970) do Conselho da Segurança, ICJ Reports (1971), pp. 4-58, and cf. Yearbook of the International Court of Justice (1970-1971) No 25, pp. 100-108.

${ }^{48} \mathrm{Cf}$. Relatorio do Ministerio das Relações Exteriores - 1976, M.R.E., 1979, p. 131 .

'I9bid.; p. 132, also for the Brazilian delegation's denouncement of apartheid in South Africa. 
años después, en la xxxir Asamblea de 1978, Brasil nuevamente asumió las causas de Namibia y Zimbabwe.

El representante del Brasil declaró en la apertura de los debates de la xxxIII Asamblea General: "esperamos ansiosamente, muy pronto, la ocasión para otorgar a la nación de Namibia -finalmente libre y soberana y con su integridad territorial preservada- nuestra bienvenida a estas Naciones Unidas. Sin embargo, nuestra cauta gratificación con el aparente progreso hacia la independencia de este país africano (...) no compensa por la continua frustración de las expectativas de la comunidad internacional con respecto a la autodeterminación del pueblo de Zimbabwe y a la abolición del régimen de apartheid ${ }^{50}$. En la misma línea de pensamiento, Brasil ofreció su apoyo en la xxxx Asamblea de 1976 a los derechos de los "palestinos a la autodeterminación y soberanía", con el entendimiento de que "la implementación de estos derechos constituyen un prerrequisito a la solución al conflicto del Medio Oriente"51. Brasil reiteró estas posiciones en la xxxiv Asamblea Gene$\mathrm{ral}(1979) 52$.

Pues bien, Brasil ha seguido una estricta política de adhesión a los derechos de las personas a la autodeterminación, exceptuando su posición inicial sobre los antiguos territorios portugueses. En efecto, Brasil ha mantenido una continua línea de apoyo a los nuévos estados (con la anterior excepción) en la Asamblea General, como también en el Consejo de Seguridad (infra). Al cubrir la situación general del Brasil en la oNU, en la xxxII Asamblea General (1977), el entonces Canciller Azeredo da Silveira destacó ante todo las intensas relaciones internacionales del Brasil, motivadas por el hecho poco usual de que comparte límites con no menos de diez países, y añadió que el Brasil posee hoy en día los suficientes intereses como para ser capaz de no compartir los errores de los su- perpoderes y de los países industrializados en sus zonas lineares de interés ${ }^{53}$. Así, al marcar la entrada de dos nuevos estados dentro de las Naciones Unidas -Vietnam y Djiboutis4, el Brasil defendió el principio de la universalidad de las Naciones Unidas.

coM.R.E., Resenha de Politica Exterior do Brasil, NQ 18, July-September 1978, p. 26.

Relatorio do Ministerio das Relaföes Exteriores - 1976, M.R.E., 1979, p. 132.

"Brazilian Mission to the United Nations, "Discurso do Ministro de Estado das Relaçōes Exteriores, Embaixador R. Saraiva Guerreiro, na Abertura do Debate Geral da xxxiv Sessao da Asscmbleias Geral das Nações Unidas", 24/9/79, p. 5 (defense of self-determination and independence for Zimbabwe and Namibia, and of the Palestinian people's rights to "self-determination, independence and sovereignty over Palestine, in accordance with the U.N. Charter"). (mimeographed, internal circulation).

${ }^{5 M}$ M.R.E., Resenha de Politica Exterior do Brasil, No 14, July-September 1977, pp. 64-65.

${ }^{2 C f}$. ibid., p. 57. - The "pragmatic line of Brazilian foreign policy proved itself by Brazil's recognition of East Germany," the Republic of Guinea-Bissau 
La adhesión del Brasil y los otros países latinoamericanos a este principio surge del trabajo preparatorio de la Carta de la oNU en Dumbarton Oaks y de la consiguiente política, por la cual el bloque latinoamericano abogó para que numerosos estados emancipados afroasiáticos fuesen admitidos a las Naciones Unidas. Más recientemente, el principio de universalidad fue invocado por la delegación brasileña durante el trabajo de la Conferencia de la onU sobre la Ley de los Tratados (Viena, 1968-69, infra) ${ }^{55}$. Sin embargo, vale la pena hacer notar que en el contexto regional (la operación de la OrA), la posición del Brasil no permite paralelos con el principio de universalidad que abogó en las Naciones Unidas, como lo ilustra el caso de la suspensión del gobierno cubano de la oEA. Tal vez las diferentes posiciones tomadas en los dos foros se deben a que la operación del así llamado sistema interamericano se refleja en poderes pequeños y medianos que tratan de contraba. lancear la hegemonía de un superpoder en el núcleo regional, un superpoder cuya preponderancia hace totalmente asimétrico y deficiente al sistema ${ }^{56}$.

Gomo se sabe, la exclusión del gobierno cubano del sistema in. teramericano fue el resultado de la Resolución de Punta del Este en 1962, seguida de sanciones adoptadas por la OEA en contra del régimen cubano. Era discutible el hecho de si tal exclusión podía efectuarse a la luz de la Garta de la OEA, que era lacónica al respecto, habiendo sido invocados los Artículos 6 y 8 del TIAR (Tratado Interamericano de Asistencia Recíproca). Aún más, estaba en discusión la representabilidad de un gobierno de un estado miembro de Ia OEA. En esa ocasión Brasil no votó en favor de la suspensión y las sanciones, alineándose con aquellos países que se abstuvieron de tomar posición frente al tema. San Tiago Dantas, en una perspicaz intervención, cuestionó legal y políticamente las medidas, colocó el problema en el contexto de la "guerra fría" y llamó la atención sobre la inutilidad y el daño de medidas coercitivas que, en vez de reducir las tensiones internacionales, las agravarían. Además advirtió que las medidas en contra de Cuba marginalizarian y precipitarían su alineación con el bloque soviético. San Tiago Dantas, recordando los problemas del subdesarrollo en América La-

(without Portugal's prior agreement) and Angola; by the establishment of diplomatic relations with mainland China; by closer political relations with the Arab world; by commercial exchange with the EEC (as Brazil's principal partner). Cf. e.g., M.R.E., Resenha de Politica Exterior do Brasil, No 2, July-September 1974, pp. 39-40 (Brazilian greeting upon Guinea-Bissau's joining the United Nations).

${ }^{\infty}$ Cf. G. E. do Nascimento e Silva, Conferéncia de Viena sobre o Direito dos Tratados, Ministerio das Relações Exteriores, 1971, pp. 42-43.

${ }^{58} \mathrm{C}$. Sepúlveda, El Sistema Interamericano: Génesis, Integración, Decadencia, $2^{a}$ ed., México, Ed. Porrúa, 1974, pp. 15, 72-75 and 117-119. 
tina, insistió enfáticamente en el principio de no intervención por parte de un estado o grupo de estados en los asuntos internos de otro estado57. La neutralidad brasileña en el caso cubano (1962) no duraría mucho porque, con los cambios internos del Brasil en 1964, éste eventualmente rompería relaciones diplomáticas con $\mathrm{Cu}$ ba (13 de mayo de 1964) ${ }^{58}$.

Con el paso de los años, algunos estados miembros de la OEA intentaron un acercamiento con Cuba (p. ej., la iniciativa del Perú en 1972 y la propuesta mexicana de 1975); la cuestión fue considerada en la reunión de Quito en 1974 y Brasil adoptó una cautelosa posición de abstención (ya no una de oposición) ${ }^{59}$. Las tendencias actuales revelan mayor flexibilidad y relajación, incluso bilateralmente entre Cuba y los Estados Unidos. Por ejemplo, el 29 de julio de 1975, veintiún estados miembros de la oEA decidieron por 16 a 3 (Chile, Paraguay y Uruguay) con dos abstenciones (Brasil y Nicaragua), dejar librado a los estados del continente el restablecimiento de las relaciones con Cuba, rompiendo virtualmente el bloqueo diplomático en contra de Guba, en efecto desde $1964^{60}$.

Volviendo al plano global, las tres posiciones u objetivos básicos de la política exterior brasileña a mediados de los años 60 fueron reveladas por el Ministro Araujo Gastro durante la apertura de la

"San Tiago Dantas, Politica ExLerna Independente, Rio de Janeiro, Ed. Civilizaçao Brasileira, 1962, pp. 105-192. Similarly, lamenting the Punta del Este majority decision to exclude Cuba from the oAs since its exclusion would jeopardize continental unity and exclude Cuba from the mainstream even more. Alceu Amoroso Lima, "A Posição do Brasil em Punta del Este", 5 Revista Brasileira de Politica Internacional (1962) No 17, pp. 5-16; the author supports Brazil for not having endorsed the oAs decision on that occasion. For the text of the resolutions at the Meeting of Punta del Este, cf. ibid., pp. 146-156; esp. pp. 151-152 (exclusion of Cuba from participating in the inter-American system).

${ }^{58}$ M.R.E., Textos e Declarações sobre Politica Externa (1964-1965), 1965, pp. 50-51, and cf. pp. 61-62. - It is known that the new concepts guiding Brazilian foreign policy. were described by then-President Castello Branco in his wellknown speech of July 31, 1964, to Rio Branco Institute graduates. He commended Brazil's immediate return to engagement with the TWest; text in: M. R. E., A Diplomacia da Revolução Brasileira, 1964, pp. 1-14; re-edited in: M. R. E., A Politica Exterior da Revolução Brasileira, 1966, pp. 1-15. - For commentaries on Brazil-United States relations, cf. W. Perry, Contemporary Brazilian Foreign Policy, Beverly Hills/London, Sage Publ., 1976, pp. 10-11, 23, 29 and 51; P. D. Bell, "Brazilian.American Relations", Brazil in the Sixties (ed. Riordan Roett), Nashville, Vanderbilt University Press, 1972, pp. $92-93$ and 80. - For a critical examination of this Brazilian warming toward North American foreign policy, cf. Celso Lafer, "Uma Interpretação do Sistema das Relaçőes Internacionais do Brasil", in C. Lafer and F. Pena, Argentina e Brasil no Sistema das Relações Internacionais, São Paulo, Livr. Duas Cidades, 1973, pp. 111.113.

${ }^{\circ}$ Cf. M.R.E., Resenha de Politica Exterior do Brasil, NQ 3, October-December 1974, pp. 26_27.

${ }^{\infty} G$ aetano Cortese, "L'eventuelle reintegration de Cuba au sein de 1'ozA", 54 Revue de droit international de sciences diplomatiques et politiques (1976), pp. 21-22, and cf, pp. 17-26. 
XviII Asamblea General de la onu en su bien conocido discurso de "las tres D": desarrollo, desarme y descolonización. El representante del Brasil hizo primero la observación de que el mundo de 1963 difería del mundo "pre-atómico" de 1945, cuando fue adoptada la Garta de la onv. Transcurridas menos de dos décadas, estaba emergiendo dentro de la onU un nuevo grupo compuesto de poderes medianos y pequeños, que trascendian ideologías y alianzas militares, para "llevar a cabo una continua lucha basada en tres temas fundamentales: desarme, desarrollo y descolonización"61. El delegado orasileño, recapitulando la posición de su país en el Comité de Desarme, compuesto por dieciocho países, reemplazó la importancia del recientemente incluido Tratado de Moscú (1963) sobre la prohibición de las pruebas nucleares en la atmósfera, defendiendo el proyecto para un tratado sobre la desnuclearización de América Latina, y endosó la idea de un pacto multilateral de no agresión (en lugar de un pacto entre miembros de la Organización del Atlántico Norte (OTAN) y del Pacto de Varsovia) ${ }^{62}$.

Pero se hizo necesario unir el ideal de seguridad económica colectiva con el ideal de seguridad política colectiva (en la víspera de la creación de la UNGTAD), porque así como la paz es indivisible, "así debe serlo el desarrollo socioeconómico de la humanidad; que es un prerrequisito a una expresión de paz"63. Los vestigios del colonialísmo constituyen el "principal obstáculo al desarrollo económico de las ex colonias que ahora se convierten en estados soberanos"64. Araujo Castro defendió el proceso de descolonización que sería "completado pacíficamente" dentro del sistema de la onv (autodeterminación de los pueblos), destacando la importante Resolución de la ONU 1.5I4 (XV) de 1960, que contenía la Declaración sobre la Concesión de Independencia a Países y Pueblos Goloniales, y el subsiguiente trabajo del Comité de Descolonización, compuesto por veinticuatro miembros ${ }^{65}$. Finalmente, al favorecer la idea de adoptar la Carta de la ONU a los nuevos tiempos, el representante del Brasil destacó que en la Conferencia de San Francisco "Brasil había sido uno de los primeros y más persistentes defensores del

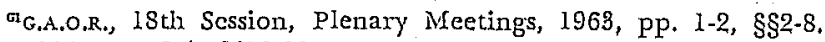

oalbid., pp. 2-4, \$\$10-20.

Ibid., pp. 4-6, $\$ \$ 21-33$.

"Ibid., p. 6, §35.

Ibid., pp. 6-7, §§ 37-40. On actions of the U.N. Committee on Decolonization, cf.: J. Sette Camara, op. cit. infra No 114, pp. 3-23; A. Khol, "The Committee of Twenty-Four and the Implementation of the Declaration on the Granting of Independence to Colonial Countries and Peoples", Reune des droits de l'homme/Human Rights Joumal (1970), pp. 21-50; F. Martine, "Le Comité de Decolonisation et le droit international", 74 Revue générale de droit international public (1970) pp. 387-389. - On Brazil's stand regarding the U.N. trusteeship system, cf. J. A. Houston, Latin America in the United Nations, N. Y., Carnegie Endowment for International Peace, 1956, pp. 165, 168-169; 174-175 and 183.184 . 
principio de flexibilidad de la 'Garta, y mantenido la propósición de que sus prohibiciones deberían ser constantemente revišadas" 60 .

El derecho de los pueblos a la autodeterminación, la importancia de la creación de la UNCTAD y el mecanismo de la ONU en las operaciones para la mantención de la paz erän temas que aparecían en los discursos del representante del Brasil (Leitao de Cunha) durante los dos años posteriores (1964-65) ${ }^{67}$. Los últimos dos temas fueron retomados por el Brasil en 1966, cuando el delegado brasileño (Juray Magalhaes) también expresó gratificación frente a la adopción de la Convención Internacional de la oNU sobre todas las formas de Discriminación Racial68 (adoptado en la sesión anterior a la Asamblea).

Tanto en 1966 como en 1965 Brasil intentó justificar frente a la Asamblea General ${ }^{69}$ la intervención de la oza en República Dominicana, a la cual había contribuido sustancialmente. Tal como el apoyo consistente del Brasil al principio de universalidad de la oNu no parece tener paralelo en la organización regional (como lo ilustra el caso cubano supra), tampoco lo es la consistente defensa del principio de no intervención dentro de la oNU como inequivoco en la organización regional, como lo ilustran las acciones del Brasil en el evento dominicano.

En la Asamblea General de 1963, el delegado brasileño expuso con orgullo que el Brasil no pertenecía a ningún bloque, pero inmediatamente admitió, en aparente paradoja, que en el nivel regional era "una parte integral de un sistema, el sistema interamericano"70, en el cual predominaba la influencia del superpoder de la región. En tal ocasión, Brasil tuvo especial cuidado de no caracte-

\footnotetext{
${ }^{06}$ G.A.O.R, 18th Session, Plenary Meetings, 1963, pp. 7-8, $\S \S 44-50$, particulariy $\$ 50$, also, for the importance attributed to the General Assembly in this revision process, "a question of experience more than of logic".

${ }^{07 C f .}$ G.A.O.R., 19th Session, Plenary Meetings, 1964, pp. 1-4, \$\$8--29; G.A.O.R., 20th Session. Plenary Meetings, 1965, pp. 2.5, $\$ \$ 8-31$ (this last speech also dealt with disarmament and alluded to the Vietnam war); "Discurso do Chanceler Leitao da Cunha na Xx Sessao da Assembleia das Naçōes Unidas (23/9/1965)", 33/34 Revista Brasileira de Politica Internacional (1966) pp. 281-289. - Even during a period of warming relations with the United States, Brazil was successful in avoiding sending troops to Vietnam; cf. Carlos Castelo Branco, "Nova Ordem Mundial - Aspectos Polfticos", A Nova Ordem Mundial (I Painel de Assuntos Internacionais da Comissao de Relações Exteriores da Camara dos Deputados), 2a ed., Brasilia, 1977, p. 119. - At the 1965 General Assembly, Brazil suggested that the best method of institutionalizing U.N. peace operations permanently "would be by including a new chapter between vr and vir, requiring reform of the Charter"; R. E. Saraiva Guerreiro, op. cit. supra No 7, p. 14.

${ }^{\circ}$ Cf. G.A.O.R., 2Ist Session, Plenary Meetings, 1966, pp. 1-4, $\$ \$ 9-26$, esp. 24.

${ }^{2}$ C.. G.A.o.R., 20th Session, Plenary Meetings, 1965, P. 2, §13; G.A.o.R., 21st Session, Plenary Meetings, 1966, pp. I-2, $\$ \$ 9-10$.

${ }^{70}$ G.A.O.R. 18th Session, Plenary Meetings, 1963, p. $\$ 9$.
} 
rizar como ingtervención lás medidas tomadas ${ }^{71}$, y en ënero de 1966 el Comité Legal Interamericano fue tan lejos como para exponer una Opinión Consultiva sobre "las diferencias entre intervención y acción colectiva"'r2. Como se sabe, Brasil contribuyó decisivamenté a la fuerza de paz de la OEA en 1965, en República Dominicana, e incluso propuso, después del hecho y sin exito, el establecimiento de una fuerza de paz interamericana permanente; una idea que fue objetada por la mayoría de los países latinoamericanos:

En la víspera de la decisión del Brasil de formar parte de la operación de la oxa en República Dominicana, Alfonso Arinos de $\mathrm{Me}$ lo Franco votó contra el proyecto en el Senado Federal, con el entendimiento de que "la subversión del sistema legal (...) representa un tremendo riesgo para cada uno de los países que forman parte del mismo sistema", y que "Ia importancia del Brasil, que (...) es un país demasiado grande para tener una pequeña polftica internacional, no puede amarrarse, ni llegar a ser satélite, ni someterse a decisiones que estén en contra de una organización legal en la cual participa y que sólo puede crear riesgos y dificultades futuras"73.

Después de algunos años, Brasil tuvo la ocasión de adoptar una posición diferente en el reciente caso de Nicaragua (1978-79), que fue debatido en la OEA y también en las Naciones Unidas. Brasil ya no favoreció la intervención de ta fuerza de paz de la oeA en el esclarecimiento de la situación nicaragüense, difiriendo de la posición de 1965 concerniente a República Dominicana, Como bien se sabe, por la adhesión de la OEA al principio de no intervención en el reciente caso nicaragüense, la iniciativa de los países del grupo

TJuracy Magalhaes, Minha Experiéncia Diplomática, Rio de Janeiro, Livr. José Olympio Ed., 1971, pp. 50 and 58.63.

TOEA, doçument OEA/Ser. $\mathrm{x} / \mathrm{VI} .2$ - GIJ-81.

${ }^{73}$ Afonso Arinos rejected any parallel between the Dominican crisis and the previous Suez Canal Crisis. He defended the idea that the Latin American States -and not only the United States unilaterally- should show a degree of initiative, decision and responsibility in arranging for continental defense. Afonso Arinos de Melo Franco, "A Intervengão em São Domingos", 21 Digesto Eco. nómico (1965) No 184, pp. 31-32 and 25-26. - A contrario sensu, in favor of the OAS action in the Dominican crisis, cf. Ilmar Penna Marinho, "Consequencias da Crise Dominicana sobre a Evolução do Sistema .Interamericano", 21 Bo. letim da Sociedade Brasileira de Direito Internacional (1965) No 41/42, pp. 69-74; Vasco Leitao da Cunha, "Polftica Externa - Documento", O Estado de São Paulo, May 28, 1978, pp. I2-13 (OAs collective action as distinct from in. tervention); J. O. de Meira Penna, Politica Externa--Seguranga e Desenvolvimento, Rio de Janeiro, Livr. Agir Ed., 1967, pp. 108-109 (also, in favor of the sanctions against the Guban government); not surprisingly, the author shows his criticism of the articulation of the "independent foreign policy" in 1963 (ibid., pp. 36-37, and dwells upon what he calls "psycho-social aspects of Brazilian foreign policy" and "its effects on the country's 'international 'prestige"

(ibid., pp. I55ss) ... 
andino contribuyó decisivamente a precipitar el reconocimiento de beligerancia a las fuerzas de oposición en Nicaragua.

Desde 1967 a 1969, los temas predominantes de las declaraciones del Brasil ante la Asamblea General se referían a su política nuclear (revocando el Tratado de Tlatelolco y repudiando el Tratado de la No Proliferación de Armas Nucleares, infra) ${ }^{74}$, el uso pacífico del espacio ${ }^{75}$, el trabajo de UNCTAD ${ }^{76}$, la descolonización y la autodeterminación de los pueblos ${ }^{77}$. En la xxrr Asamblea General (1967), Brasil fue elegido para formar parte en el Comité Ad Hoc, de 35 miembros, para examinar el tema de los fondos marinos ${ }^{78}$, y en los dos años siguientes participó en el Comité, que intentaba establecer un régimen internacional y mecanismos para los fondos marinos más allá de las jurisdicciones nacionales ${ }^{79}$ (cf. Conferencia del Derecho del Mar, infra). Después de dos años de negociaciones, la xxv Asamblea General (1970) adoptó una declaración de principios básicos sobre el régimen internacional que regula la explotación y uso del mar y los suelos oceánicos fuera de los límites de la jurisdicción nacionalso (el límite del mar territorial del Brasil fue extendido a 200 millas en ese mismo año, cf. infra). Ya en 1970 la delegación brasileña tomó parte activa en los procedimientos de la Conferencia del Comité de Desarme, que originó una Resolución de la Asamblea General recomendando que fuese abierto para firmar el Tratado sobre Armamentos Nucleares del Suelo Oceánico ${ }^{81}$. Más tarde, Brasil insistió nuevamente en la posición de que todos los países son responsables por el proceso de desar$m^{82}$. En la Xxxi Asamblea General (1976), Brasil favoreció el principio de las armas nucleares (a pesar de haber repudiado los tér-

"Relatorio do Ministerio das Relações Exleriores - 1967, M.R.E., 1970, pp. 127-132, and cf. p. 123; Discurso de Representante do Brasil (Magalhaes Pin.. to), G.A.O.R., 22nd Session, Plenary Meetings, 1967-1968, pp. 2-3, \$§15-19 and 26; Relatorio do Ministerio das Relaçóes Exteriores - 1969, M.R.E., 1973, p. 79.

${ }^{75}$ Relatorio do. Ministerio das Relações Exteriores - 1969, pp. 76-77.

${ }^{\pi B}$ G.A.O.R., 22nd Session, Plenary Meetings, 1967-1968, pp. 1.2, \$\$18-14 and cf. p. 3 §28; Relatorio do M.R.E. - 1969, p. 81 .

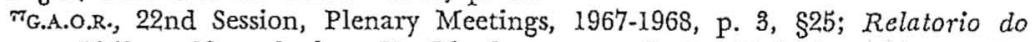
M.R.E. - 1969 p. 82, and cf. p. 81. Cf. also, M.R.E., Gestao Malgahaes Pinto - Relatorio Final, 1969, pp. 40-44 and 118-126.

${ }^{\pi}$ Relatorio do M.R.E. - 1969, p. 78.

TRelatorio do M.R.E. - 1969, p. 78.

${ }^{80}$ Relatorio do M.R.E. - 1970 , pp. 92-93.

sIbid., p. 94; and cf. No 133 infra.

${ }^{82}$ CE. M.R.E., Resenha de Politica Exterior do Brasil, No 17, April-June 1978. p. 89, and cf. pp. 81-85; Res. Pol. Ext. do Brasil No 18, July-September 1978, p. 27; Rles. Pol. Ext. do Brasil, No 13, April-June 1977, pp. 23-24 (Brasil's position in favor of the ban on nuclear arms in Latin America). - For statements by BraziI at the Conference of the Disarmament Committee in Geneva, cE., e.g., M.R.E., Documentos de Politica Externa, vol. v, 1971, pp. 93-95; Doc. Pol. Ext., vol. vi, 1972, pp. 125-131; Doc. Pol. Ext., vol. vII, 1973, pp: I53-154 and $173-177$. 
minos del Tratado de No Proliferación de Armas Nucleares, cf: infra), como por el derecho de los palses en desarrollo a acceder a la tecnología nuclear para propósitos pacíficos" $\$ 3$.

Al abrir Ios debates generales de la xxvr Asamblea General el 27 de septiembre de 1971, el entonces Ministro de Relaciones Mario Gibson Barboza, sintetizó la línea básica de la Gancillería sobre la oposición del Brasil a la división del mundo en zonas de influencia ${ }^{84}$. Dos años después, el 24 de septiembre de 1973, en la apertura de los debates generales en la Xxvir Asamblea General, ofreció apoyo para la política de détente, que fue nuevamente seguida por los superpoderes y por los poderes emergentes ${ }^{85}$.

Es apropiado mencionar aquí el interesante paralelo entre las acciones del Brasil en la Asamblea General y en el 'Consejo Económico y Social (ECOSOC) con respecto a este punto. En la Xxv Asamblea General, la delegación brasileña tuvo un papel considerable en los debates que condujeron a la adopción de una Resolución sobre el fortalecimiento de la seguridad internacional colectiva ${ }^{86}$. Durante esos debates, Brasil adquirió la posición de actuar como vocero del grupo latinoamericano ${ }^{87}$. La Resolución adoptada, considerada "el primer paso concreto hacia la reactivación diplomática de Ia ONU", incluyendo inter alia los siguientes puntos básicos en la posición brasileña: reafirmación de los principios y propósitos de la Garta de la onv, y la primacía de las obligaciones contenidas en la Carta sobre todas las otras obligaciones; y afirmación de la existencia de un "nexo directo entre el fortalecimiento de la seguridad internacional, el desarme y el desarrollo económico"s8.

* Relatorio do Ministerio das Relações Exteriores - 1976, M.R.E., 1979, p. 133. Regarding peaceful use of outer space, at the U.N. Committee on Outer Space negotiations for the Moon Treaty, Brazil claimed for the moon the "legal nature of common heritage of mankind", and furthermore, judged it tppropriate to conclude the traety bofore the outer space powers began exploiting the moon's resources; ibid., p. 129.

${ }^{B} 1_{\text {M.R.E. }}$ Documentos de Politica Externa, vol. v, 1971, p. 242, but cf., in this regard, the critical and cautions observations of Oliveiros Ferreira, "A Evolu. ção da Política Externa Brasileira", "A Nova Ordem Mundial (I Painel de Assuntos Internacionais da Comissão de Relações Exteriores da Camara dos Deputados), qa ed., Brasilia, 1977, pp. 340-343.

8TM.R.E., Documentos de Politica Externa, vol. vII, 1973, pp. 188.189 and 192.

${ }^{58}$ Relatorio do Ministerio das Relações Exteriores - 1970, M.R.E., 1973, pp. 87 and $90-91$.

stibid., p. 90.

${ }^{85}$ The resolution further expounds on the capacity of the General issembly and the Security Council, and mentions the II Decade of Development; ibid., pp. 90-91. - On international collective security, cf. also, the September 28, 1970, speech of the head of the Brazilian delegation (J. A. de Araujo Castro) on "Fortalecimento da Segurança Internacional, in M.R.E., Documentos de PoIttica Externa, vol. IV, 1969-1970, pp. 211-221. - On the resolution containing the Declaration on International. Security, adopted by. 124 votes in favor and 
Hoy, una década después, Brasil permanece fiel a su ṕropósito de continuar "trabajando por el fortalecimiento de la oNU para mantener Ia paz y seguridad internacionales ${ }^{89}$ (cf. infra).

Ási, durante los últimos años en el Ecosoc (sesiones 52 y 53) y la Asamblea General, como también en el Cónsejo Permanente de la OEA, Brasil ha defendido insistentemente la proposición de una. seguridad económica colectiva ${ }^{\circ 0}$, como un dinámico nuevo concepto que complementa el clásico y estático concepto de seguridad politica colectiva ${ }^{91}$. Esta nueva noción implicaría iguales oportunidaldes para el desarrollo económico de Ios países miembros. Brasil hizo una propuesta al respecto en 1974, explicando en 1977, ante Ia Asamblea General, que la idea de la seguridad económica colectiva para el desarrollo mostraba que "Ia justicia social y el progreso económico son esenciales a un sistema de garantías entre los estados ỳ, aún más, son inseparables de propósitos de paz y seguridad"92. En la VII Sesión Especial de Ia Asamblea General (1977), Brasil propuso un Acuerdo General sobre Comercio entre Países Desarrollados y en Desarrollo, con el propósito de "establecer nuevas reglas del juego para el comercio Norte-Sur"93.

two abstentions, cf. [Axaujo Castro], "O Pensamento de Araujo Castro", 1 Relaçöes Internacionais - Brasilia (1978), p. 59.

${ }^{8}$ Brazilian Mission to the United Nations, op. cit, supra N8 52, p. 3 and. cf. p. 10 (position favoring return to the North-South dialogue). (Mimeographed, internal circulation). At the recent U.N. Conference on Science and Technology for Development (UNCSTD), Vienna, 1979 - cf. ibid., pp. 15-16), in demonstrating interest in intensifying its participation in multilateral programs for scientific and technological cooperation, Brazil recognized the fundamental role developed by the U.N. General Assembly in "defining conceptual and quantitative goals" regarding international cooperation in science and technology.

NAlready in November 1966, then-Brazilian Minister for Foreign Relations alluded to the concept of collective security at the Ievel of international relations; Juracy Magalhaes, op. cit. supra No 7I, p. 15.

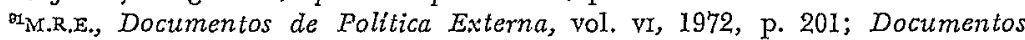
de Politica Externa, vol. vir, 1973, p. 260. For a study on this subject, cf., e.g.s Hildebrando Accioly, Sistemas Regionais de Segurança Coletiva; a Posição do Brasil na OEA, Ministerio das Relações Exteriores/Instituto Rio Branco, 1955, pp. 1.17.

${ }^{92}$ M.R.E., Resenha de Politica Exterior do Brasil, No 14, July-September 1977, pp. 61-62. In this regard, Brazil actually defended an "updating" of the U.N. Charter (taking into account article 109) to reevaluate and free it of content springing from the out-dated power structure of the immediate post-war period; cf. M.R.E., Documentos de Politica Externa, vol. vI, 1972, pp. 203-204. On the Brazilian position yis-a-vis the revision project of the entire inter-American system, after 1972 cf. M.R.E., Documentos de Politica Externa, vol. vil, 1973, pp. 273-280.

${ }^{\circledR C}$ C., for details, M.R.E., Resenha de Politica Exterior do Brasil, No 6, JulySeptember 1975, pp. 31-33; and cf. also: Res. Pol. Ext. do Brasil, No 9, AprilJune 1976, p. 93; Res. Pol. Ext. do Brasil, No 10, July-September 1976, p. 62; Res. Pol. Ext. do Brasil, No 14, July-September 1977, p. 66. 
Luego, después de su elección para un mandato de tres años en el Ecosoc ${ }^{94}$, Brasil apoyó el programa de la II Década de Desarrollo en debates con los países en desarrollo y defendió, inter alia: a) mayor acceso de los productos de los países en desarrollos a mercados de los países altamente industrializados $(.$.$) ; b) mayor par-$ ticipación de las marinas mercantes de los países en desarrollo en los mercados internacionales de carga; c) mayor movilización de capital en los países en desarrollo para proyectos en naciones menos favorecidas (...); d) mayor acceso de estos países a las tecnologías desarrolladas en países industrializados $(\ldots)^{\prime 95}$. Es útil destacar el apoyo de la delegación brasileña en el Ecosoc a un proyecto que establecía el Comité Permanente sobre Recursos Naturales, al cual Brasil fue elegido en la xxv Asamblea ${ }^{96}$.

Los esfuerzos de la onv para crear este comité fueron de lenta evolución. Durante el período 1952-1962 —una década de nacionalizacion- Ias resoluciones de la onu hicieron referencia al deseo de usar libremente recursos naturales y riquezas. Ya en 1958, la Asamblea General habia establecido un Comité Permanente sobre Recursos Naturales". En los diez años siguientes, ya se hablaba de soberanía permanente sobre los recursos naturales, un tema que atrajo la constante atención de la Asamblea, desde la Resolución renovada 1.803 (XVII) en 1962, hasta la Resolución 3.171 (xxvIrI) en 197307. Con el apoyo del Brasil, ecosoc creó el Comité Permanente sobre Recursos Naturales en julio de 1970, que desde 1971 ha servido como un órgano técnico y de coordinación.

Tres años más tarde, en la xxrx Asamblea de 1974, Brasil insistió que "es un derecho inherente en la soberanía de un estado el hacer libre uso de los recursos naturales en su territorio"9s. Brasil

When Brazil reccived an affirmative vote from 121 of the 126 U.N. members; Relatorio do Ministerio das Relaşöes Exteriores - 1969, M.R.E., 1973, p. 84.

${ }^{05}$ Relatorio do Ministerio das Relaçóes Exteriores - 1970, M.R.E., 1973, pp. 95.96; Brazil was in favor of suggestions for administrative and political reformulation of the U.N. Development Program; ibid., p. 97, and cf, more recently, M.R.E., Resenha de Politica Exterior do Brasil, No 12, January-March 1977, pp: 63-64.

orbid., p. 96. - On Brazil's position in the Ecosoc, cf. also, M.R.E., Documentos de Política Externa, vol. Ir, 1969-1970, pp. 143-153; Doc. Pol. Ext., vol. v; 1971, pp. 153-162. And cE "constructive criticism of the Brazilian delegation to the I U.N. Decade of Development, on the occasion of the Ecosoc XIIX Session. as discussed in: Jorge de Carvalho e Silva, "O Brasil em Frente aos Grandes Problemas Polfticos Internacionais Contemporáneos", in M.R.E., Documentos de Politica Externa, vol. IV, 1969-1970, pp. 184-185.

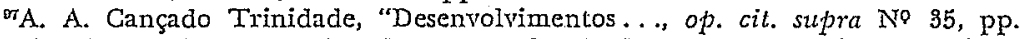
138-146; A. J. Lleonart y Amselem, Derecho de los Estados a Disponer Libremente de sus Recursos Naturales, Madrid, Cons. Sup. Invest. Cient./Instituto Francisco de Vitoria, 1976, pp. 274-475.

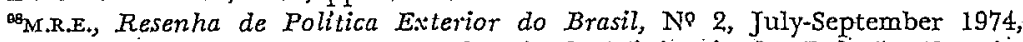
p. 43; and cf. in the same regard, Relatorio do Ministerio das Relaçöes Exterio- 
abogó en otras ocasiones por este mismo punto de vista, como en la Conferencia sobre el Medio Ambiente en 1972 ( $\mathrm{cf}$. infra). El año 1974 fue el más significativo en el plano multilateral, cuando la Asamblea General aprobó en mayo y diciembre tres documentos pertinentes: la Declaración sobre el Establecimiento de un Nuevó Orden Internacional99, el Programa de Acción sobre el Establecimiento de un Nuevo Orden Económico Internacional100, y la Carta de los Derechos y Deberes Económicos de Ios Estados ${ }^{101}$.

Este último documento, fruto de una iniciativa mexicana en la reunión de la III UNCTAD en Santiago en 1972, fue adoptado con el sólido apoyo de los países desarrollados, y puede ser mejor apreciado junto con los otros dos documentos mencionados. Juntos, ellos enfatizan que los países en desarrollo necesitan y afirman su derecho en comprometerse en un comercio internacional libre de discriminación, sustentado en diferentes sistemas económicos, sociales y políticos. Los documentos, basados en el principio de la igualdad jurídica de los estados, urgen una mayor cooperación en las relaciones económicas internacionales, contemplando las necesidades de los países menos desarrollados. Ellos claman por una política económica internacional a través de los mecanismos de la oNU, advirtiendo que los estados deben estar conscientes de los nocivos efectos que pueden tener sus políticas económicas nacionales sobre la economía y los intereses de otros países, particularmente los países menos desarrollados ${ }^{102}$.

Los tres documentos proponen la extensión y perfección de los sistemas generalizados de preferencias para tarifas, no recíprocos y no discriminatorios, en beneficio de los países en desarrollo. Más aún, ellos afirman en términos inequívocos el derecho de todos los estados para guiar y controlar el capital extranjero y las actividades de las empresas multinacionales de acuerdo con sus propios deseos, estableciendo patrones guías de nacionalización y expropiación ${ }^{103}$.

Algunos estados participaron en el bosquejo de la Carta, proceso durante el cual presentaron sus propuestas diferentes bloques. Hubo oposición individual y escasa a ciertas provisiones. Una fue

res - 1976, M.R.E., 1979, p. 133; M.R.E., Documentos de Politica Exterma, vol. vII, 1973, pp. 203.204.

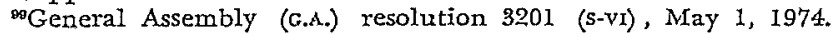

${ }^{200} \mathrm{G} . A$. resolution 3202 (S-YI), May 1 , 1974.

${ }^{101}$ G.A. resolution 3281 ( $\mathrm{xxIx}$ ), December $12,1974$.

${ }^{102}$ A. A. Cançado Trindade, "Desenvolvimentos..., op. cit. supra No 35, pp. 145-I46.

${ }^{103} \mathrm{Cf}$. ibid., p. 145 , - At the regional level, the oAs Permanent Council proposed measures for control of multinational companies in Latin America, in a resolution approved unanimously in July 1975 (e.g., "code of conduct" project). Reference was made to the Charter of the States' Economic Rights and Duties, and to related studies undertaken by the Inter-American I.egal Commission. Cf. ibid., pp. 145-I46. 
de Brasil, junto con un pequeño número de otros estados, contra la propuesta de Argentina para insertar en la Carta un sistema previo de información entre los estados de información y consulta en la explotación de recursos naturales comunes a dos o más estados. Contrariamente a lo que ocurrió en la Conferencia sobre el Medio Ambiente en 1972 (cf. infra), esta vez las objeciones del Brasil no tuvieron éxito, y la propuesta argentina, apoyada por algunos estados miembros del grupo dé trabajo, llegó a ser el Artículo 3 de la 'Carta104. Esto es simplemente uno de los ejemplos de la controversia en el diseño de la Carta, pero ella no opacó su exitosa adopción el 12 de diciembre de 1974, por una mayoría de 120 contra 6 , y 10 abstenciones.

Así, ya en la xxix Asamblea de 1974, Brasil consideró que "es el derecho inherente de la soberanía de los estados usar librementè los recursos naturales en sus territorios"105. Más tarde, en la apertura de la xxxr Asamblea General el 27 de septiembre de 1976, la delegación brasileña ofreció su apoyo al establecimiento de un Nuevo Orden Económico Internacional ${ }^{106}$. En las Naciones Unidas ${ }^{107}$, como también en la $\mathrm{OEA}^{108}$, Brasil condenó las prácticas proteccionistas (por paises altamente industrializados) conducentes a una creciente oposición al establecimiento de relaciones económicas internacionales más justas $\mathrm{y}$ equitativas.

\section{Las posiciones del Brasil en el Consejo de Seguridad DE LAS NACIONES UNIDAS}

Son bien conocidos los esfuerzos del Brasil para mantener su posición como un miembro elegido (por mandatos sucesivos desde 1920 a 1925) del Consejo de la ex Liga de las Naciones. Ellos culminaron en el retiro del Brasil del Consejo de la Liga de las Naciones en 1926109. En la era de las Naciones Unidas y para fines

${ }^{10} \mathrm{~J}$. Castañeda, "La Charte des droits et devoirs economiques des Etats. Note sur. son processus d'elaboration". 20 Annuaire français de droit intemational (1974), pp. 45 and 47 , and cf. pp. 31-56.

${ }^{106}$ M.R.E., Resenha de Politica Exterior do Brasil, No 2, July-September 1974, p. 43.

${ }^{106} \mathrm{Cf}$. M.R.E., Resenha de Politica Exterior do Brasil, No 10, July-September 1976, pp. 71-77; and cf. also M.R.E., Res. Pol. Ext. do Brasil, No 7, October-De. cember 1975, pp. 115-122. Gf. commentary by A. Azeredo da Silveira, "O Brasil e a Nova Ordem Internacional", A Nova Ordem Mundial (I Painel de Assuntos Internacionais da Comissão de Relações Exteriores da Cámara dos Deputados), $2^{\text {a }}$ ed., Brasilia, 1977, pp. 7-18.

${ }^{10}$ Xxxmr U.N. General Assembly (1978), M.R.E., Resenha de Politica Exterior do Brasil, No 18, July-September 1978, p. 27.

${ }^{103}$ VIII OAS General Assembly, M.R.E., Resenha de Politica Exterior do Brasil, No 17, April-June 1978, p. 45.

${ }^{100}$ For a critical report on the Brazitian position, cf. José Carlos de Macedo Soares, Le Bresil et la Societé des Nations, Paris, Pedone, 1927, Pp. I45-I46, I50- 
de los años 70, Brasil había completado cinco mandatos como miembro elegido no permanente del Consejo de Seguridad de la ONU, desde 1946 a 1947, 1951 a 1952, 1954 a 1955; 1963 a 1964, y 1967 a 1968. De ahi en adelante, antes que perseguir nuevas reelecciones al Consejo de Seguridad, Brasil enfocó su atención más directamente en órganos que estaban preocupados con problemas económicos, tales como el Ecosoc. Documentos clasificados de la oNu proporcionan datos que identifican las posiciones del Brasil como miembro elegido del Consejo de Seguridadi10.

Así, Brasil participó en debates y medidas del Consejo relacionadas con importantes crisis internacionales, tales como la de Grecia y Egipto en 1947, Siria y Líbano en 1946, Guatemala (1954), Panamá (1964), India y Pakistán (1964) y Chipre (1964), entre otros $^{111}$. En ciertas ocasiones Brasil asume posiciones basadas en principios claros, como durante los debates de 1964 y 1968 sobre el appantheid en Sudáfrica, donde Brasil condenó todas las formas de discriminación racial, particularmente cuando era practicada por un estado miembro, en flagrante violación de la Carta de la oNU ${ }^{112}$. También, con respecto al régimen de pacto de Rodesia del Sur, Brasil abogó por una enérgica censura por parte del Consejo de Seguridad Regional en 1968113.

A mediados de 1970, Brasil apoyó el principio de la autodeterminación de los pueblos muy claramente, a través de la declaración de su representante (Sette Camara) en el Gonsejo, concerniente a

151, 167-172, 177, 190-191 and 194.195; also in Portuguese, José Carlos de Macedo Soares, O Brasil e a Sociedade das Naçöes, Paris, Pedone, 1927, chap. IY, pp. I11-143. On Brazil's withdrawal from the League of Nations cf. also: Afonso Arínos de Melo Franco, Um Estadista da República, Río de Janeiro, Ed. Nova Aguilar; 1976, chap. xxvII, pp. 927-956, and cf. also, chaps. XxvI-xxvi, pp. 885-927; R. Ferreira de Mello (org.), Textos de Direito. Internacional e de Fitstoria Diplomática de 1815 a 1949, Rio de Janeiro, 1950, pp, 289.299. - On the segregation of duties between the League Assembly and Council, cf. the reflections of Raúl Fernandes, A Sociedade das Naşôes, Rio de Janeiro, Imprensa Nacional, 1925, pp. 20-27.

${ }^{110}$ In particular, see the Anuarios of the U.N. relevant to the years of Brazilian mandate in the Council and the Repertorio da Prática do Conselho de Segurança da oNu. As well, see the data survey conducted by my former students at Rio Branco Institute (Class of 1979), now Terceiros Secretarios do Brasil, Ralph Peter Henderson, Eduardo Ricardo Gradilone Neto, Paulo César de Camargo, Marcos Vinicius Pinta Gama and Maryani Bravo Leite, - entitled, "A Participaçäo do Brasil no Conselho de Segurança da ONU", in Instituto Rio Branco, Trabalhos de Direito Internacional Publico (presentation by A. A. Cançado Trindade, Brasilia, M.R.E./rRBr, 1979, pp. 28-76) (internal circulation). ${ }^{1 x}$ Cf. ibid., pp. 45-59. For Brazil's position on the Gyprus issue before the Security Council (1964), cf. 26 Revista Brasileira de Politica Internacional (1964), pp. 347-348; and on the Congo issue before the Security Council, cf. speech on December 16, 1964, by Ambassador José Sette Camara, in 27 Revista Brasileira de Politica Internacional (1964), pp. 63I-634.

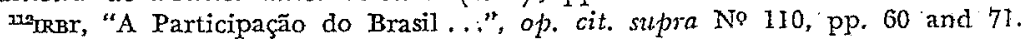
'nsIbid., p. 74. 
la admisión de Ios nuevos estados miembros de la onu (Malawi, Malta, Zambia, seguido por Yemen del Sur, Mauricios, Swailandia y Guinea Ecuatorial) 114. Sin embargo, al mismo tiempo Brasil evitó (1967) endosar la posición del Consejo de Seguridad condenando las políticas portuguesas en Africa ${ }^{115}$, que era una posición minoritaria en la onU, y ello pudo haber conducido a Brasil a cierto aislamiento diplomático durante ese período110, a peșar de sus previos esfuerzos a principio de 1970 para acercarse al mundo afroasiático a través de proponentes de la política: exterior independiente del Brasil117. Así, mientras Brasil apoyó consistentemente la política de descolonización de la $\mathrm{ONU}^{118}$, las relaciones especiales mantenidas con Portugal impidieron resultados más positivos ${ }^{119}$. Sin embargo, el panorama varió después de los cambios políticos en Portugal en abril de 1974, y la actual línea pragmática del Brasil puede ser ilustrada a nivel bilateral, por ejemplo, por su reconocimiento de Angola ${ }^{120}$.

nsIbid., pp. 61-62, 68 and 74-75, particularly pp. 61-62, for the statements of Sette Camara confirming that Brazil has always been an adversary of colonialis. For a study of the matter by the Ambassador, today Judge of the International Court of Justice, cf. J. Sette Gamara, "O Fim do Colonialismo", 38/39 Tempo Brasileiro (1974), pp. 3.23.

${ }^{110} \mathrm{CF}$. IRBr, "A Participação do Brasil...", op. cit. supra No 110, pp. 64 and 68.

1xibid., p. 35. That Salazar's colonialism may be "alienated" Brazil's foreign policy in this regard, cf., Jose Honorio Rodrigues, "The Foundations of Brazil's Foreign Policy", 38 International Affairs (1962), p. 35. Cf. also comments by M. Y. Leite Linhares, "Brazilian Foreign Policy and Africa", 18 The World Today - London (1962), pp. 536-540.

${ }^{117}$ Afonso Arinos de Melo Franco, "Portugal, Brasil, Africa", 38/39 Tempo Brasileiro (1974), pp. 70-72, also, for his critique of the traditional approach of Brazilian diplomacy to that of the Portuguese regarding Africa; Afonso Arinos de Melo Franco, Planalto (Memorias), Rio de Janeiro. Livr. José Olympio Ed., 1968, pp. 187-197; San Tiago Dantas, op. cit. supra No 57, pp. 22-23 (Brazil's solidarity with those peoples then aspiring to emancipation); Janio Quadros, "A Nova Política Externa Brasileira", 3 Relaçöes Intemacionais - Brasilia (1978) , pp. 75-77, re-edited by Janio Quadros, "Brazil's New Foreign Policy", 40 Foreing Affairs (1961-1962), pp. 19-27. On Brazil and the Afro-Asiatic block, cf. also A. J. Bezerra de Menezes, Asia, Africa $e$ a Política Independente do Brasil, Rio de Janeiro, Zahar, 1961, pp. 47-75 and 109-112; A. J. Bezerra de Menezes, O Brasil e o Mundo Asio-Africano, Rio de Janeiro, Ir. Pongetti Ed., 1956, pp. 329-381; José Honorio Rodrigues, Interesse Nacional e Politica Externa, Rio de Janeiro, Ed. Givilizaçăo Brasileira, 1966, pp. I55-179 (Afro-Brazilian relations) and $65-75$ and 180.215 (independent foreign policy); José Honorio Rodrigues, Brasil e Africa: Outro Horizonte, vol. 2 rev., Rio de Janeiro, Ed. Civilizaçăo Brasileira, 1964, pp. 370-44I (Brazilian policy in the U.N. toward Africa); E. Fischlorwitz, "Subsidios para a 'Doutrina Africana' do Brasil", 9 Revista Brasileira de Politica Internacional (1960), pp. 82-95.

${ }^{I 8} \mathrm{Cf}$. J. Sette Camara, op. cit, supra No 114, pp. 3-23; and cf., e.g., more recently; M.R.E., Resenha de Politicá Exterior do Brasil, No 12, January-March 1977, p. 277.

${ }^{119} \mathrm{Cf}$, e.g., Juracy Magalhaes, op. cit. supra No 71, pp. 17-18.

${ }^{200}$ On oscillations in Brazil-Portugal-Africa politics; cf., exg., C. Estevam Mar̀- 
Al asumir la presidencia del Consejo de Seguridad, el representante brasileño J. A. de Araujo Castro pronunció incisivos discursos en 1965, advirtiendo contra la pasividad del Consejo frente a la carrera armamentista y a su inefectividad frente a la invasión checoslovaca ${ }^{121}$; el delegado también atacó problemas de naturaleza institucional que volvían inoperativo al Consejo ${ }^{122}$ (p. ejemplo, crítica al derecho de veto de los "cinco grandes" del Consejo ${ }^{123} \mathrm{Va}$ Ie la pena recordar que otro delegado brasileño, Philadelpho Azevedo, juez en la Corte Internacional de Justicia, actuando en su capacidad profesional individual, opinó en forma diferente en el caso de la Competencia de la Asamblea General para Admitir un Estado en las Naciones Unidas (1950), en objeción a un posible "abuso de poder" a través del ejercicio del derecho a veto reservado a los miembros permanentes del Consejo de Seguridad ${ }^{124}$.

De hecho, el privilegio de veto produjo abusos. La Unión Soviética tuvo un record de 105 vetos hasta marzo de 1970, Gran Bretaña cuatro, Francia tres, los Estados Unidos uno y China Nacionalista dos ${ }^{125}$. Pero es sabido que en la práctica las Naciones Unidas

unns, "A Evolução da Política Externa Brasileira na Deçada 64/74", 12 Estudos Cebrap (April-June 1975), São Paulo, Ed. Cebrap, pp. 66 and 95-96. Cf. earlier, "O Brasil e a Questão de Angola na onv" (documents), I7 Revista Brasiteira de Politica Internacional (1962), pp. 143-146; San Tiago Dantas, op. cit. supra-No 57, pp. 195-200 (Brazil and the Angola issue in the U.N.).

${ }^{12} \mathrm{Cf}$. IRBr, op. cit. supra No 110, pp. 72,73 and 75; Rolando Mota Sardenberg, "O Pensamento de Araujo Castro, "Relações Internacionais - Brasilia (1980), pp. 57-59.

12C. IRBr, op. cit. supra No 110, p. 73.

${ }^{203}$ [Araujo Castro], "O Pensamento...", op. cit. supra No 88, pp. 54-55.

12 A. A. Cançado Trindade, "Aspectos da Jurisprudencia da Coste Internacional de Justiça, Atraves do Votos dos Juizes Philadelpho Azevedo e Levi Carneiro", 4 Relações Internacionais - Brasilia (1979), pp. 35-38, and cf. pp. 3439. Additionally, it is worth remembering that Brazil acted as a litigating party before the Permanent Court of International Justice (precursor to the current International Court of Justice) in the case of the Brazilian Loans, France vs. Brazil, 1929). The dispute dealt with a clause regulating gold payments of Brazilian federal bonds (issued in France from 1909 to 1911), which Brazil had tried to pay -after World War $\mathrm{I}-$ in the current value in French francs. The decision of the Court of Hague, accepted by the Brazilian government, favored payment of the debts in the value corresponding to that of the weight of the gold specified in the contract. Cf. Corte Permanente de Justiça Internacional, Serie A, 1929, No 20/21.

10I. L. Claude, Jx., Swords into Plowshares, 4th ed., N. Y., Random House, 1971, chap. 8, pp. 141-162. - The dubious and incoherent practice of the Security Council permanent members stands out regarding, e.g., the determination of matters which supposedly fall under the states' "exclusive" national competence. Cf. in this regard, D. R. Gilmour, "Article 2 (7) of the y.N. Charter and the Practice of the Permanent Members of the Security Council"; Australian Yearbook of International Law (1967), pp. 153-210; and for a more recent study, cf. A: A. Cançado Trindade, $O$ Estado $e$ as Rlelações Internacionais: O Dominio Reservado dos Estados na Pratica das Nações Unidas e Organizaçôes

$$
\left[\begin{array}{llll}
4 & 3 & 0
\end{array}\right]
$$


hicieron un esfuerzo para sobrepasar la inmovilidad $\mathrm{Y}$ la parálisis del Consejo de Seguridad, derivadas del abuso de veto, adoptando la penosa resolución de Unirse para la Paz de 1950, que extendió el papel de la Asamblea General126. Por tanto, parece que la crítica al texto de la Carta de la oNu debe ser reducida por una idén. tica atención a la práctica de la organización, que ha servido como un elemento de interpretación progresiva de los poderes conferidos a sus órganos ${ }^{127}$.

Ejemplo de la participación brasileña en medidas adoptadas por el Consejo de Seguridad se encuentran en las fuerzas de paz o emergencia de las Naciones Unidas. En más de una ocasión Brasil participó en misiones de paz: envió tropas al Congo en 1960 y estuvo entre las fuerzas de la ond en Chipre. Sin embargo, su actuación más conocida fue en las fuerzas de emergencia durante la crisis de Suez, donde por años, hasta 1967, ayudó a prevenir que creciera aún más el conflicto en el Medio Oriente ${ }^{128}$.

Es importante destacar la oposición del Brasil en el Consejo de Seguridad, en junio de 1965, al Tratado de No Proliferación de Armas Nucleares ${ }^{129}$. La posición del Brasil sobre este tema tam. bién fue reiterada en la Asamblea General, cuando en 1968 el Ganciller Magalhaes Pinto condenó la distinción sancionada en dicho tratado entre países nucleares y no nucleares ${ }^{130}$; su critica al así llamado: "congelamiento del poder mundial" fue repetido por otros miembros del Cuerpo Diplomático del Brasil en otras ocasiones ${ }^{131}$. Igualmente, Brasil tomó parte en la Conferencia del Comité de Desarme de la onu (creado en 1962) ${ }^{132}$ y en las negociaciones de

Regionais, Brasilia, Editora Universidade de Brasilia, 1979, pp. 17-27, 41-50, esp. p. 21.

${ }^{12 \mathrm{CE} .}$ A. A. Cançado Trindade, Principios do Direito Internacional Contemporáneo, Brasilia, Editora Universidade de Brasilia, I981, chap. VI, pp. I87-221.

${ }^{127}$ A. A. Cançado Trindade, op. cit. supra No 97, pp. 123-133.

${ }^{129}$ Mario Gibson Barboza, "As Nações Unidas e o Brasil", in M.R.E., Documentos de Politica Externa, vol. IV, 1969-1970, p. 189; and cf.: IRBr, op. cit. supra No 110, p. 66; Juracy Magalhaes, op. cit. supra No 71, p. 50, and cf. p. 96 on the favorable position of Brazil (in 1965), toward permanent institutionalization of the OAS Inter-American Defense Force-a position that was unsucessful.

Which for Brazil was not inspired by the U.N. Charter, as opposed to what occurrred with the Treaty of Tlatelolco; cf. IRBr, op. cit. supra No 110, p. 75 .

${ }^{130}$ M.R.E., Documentos de Política Externa, vol. Ir, 1967.1968, pp. 89-94. And cf. H. J. Rosenbaum and G. M. Cooper, "Brazil and the Nuclear Non-Proliferation Treaty", 46 International Affairs (1970), pp. 74-90; and cf. No 135 infra,

${ }^{181}$ Cf. e.g., J. A. de Araujo Castro, "O Congelamento do Poder" (in "O Pen. samento..."), op. cit. supra No 88; p. 53.

${ }^{132} \mathrm{On}$ Brazil's beginning participation in the Disarmament Committee, cf. San Tiago Dantas, op. cit. supra No 57, pp. 203-222; San Tiago Dantas, "O Brasil e o Desarmamento", 27 Revista Brasileira de Politica Internacional (1964), pp. 485-491; M.R.E., O Brasil na Conferéncfa do Desarmamento, 1963, pp. 5-43. also, the critical observations of de Afonso Arinos de Melo Franco, "A A ONu e a 
la onu sobre desarme133. En 1970, sin embargo, al defender "el desarme completo bajo control internacional efectivo", Itamaraty también expuso que los temas sobre desarme estaban conectados con el cumplimiento de la cooperación internacional para el desarrollo económico, colocando la responsabilidad frente al desarrollo económico en los esfuerzos nacionales internos ${ }^{134}$.

Los argumentos actuales fundamentales a la política nuclear del Brasil - cuyo análisis sobrepasa las metas de este trabajo- se resumen en los párrafos 25 a 26 de un documento presidencial fechado el 10 de marzo de 1977, invocando inter alia el Tratado de TlateIolco de 1967 y sus dos Protocolos Adicionales (prohibiendo las armas nucleares en América Latina), de entre los seis acuerdos internacionales desde 1958 y relacionados con la cuestión de la no proliferación de armas nucleares. El documento presidencial también reafirma el rechazo del Brasil al Tratado de No Proliferación ${ }^{135 .}$

Es también útil destacar el Proyecto del Brasil para "fortalecer la seguridad internacional", que contiene sugerencias para los métodos de trabajo del Consejo de Seguridad y fue presentado a la Asamblea General de la oNu en 1970 (cf. supra), AI responder al pedido del año anterior a la Asamblea General, la propuesta del Brasil defendió la revisión del mecanismo de seguridad colectiva, incluyendo un mayor uso de las posibilidades encontradas en el $\mathrm{Ca}$ pítulo vi de la Garta, esto es, mecanismos diplomáticos usados oca-

Política Exterior do Brasil", 20 Digesto Econdmtco (1962) No 168, pp. 130-133; Mario Gibson Barboza, "As Nações Unidlas e o Brasil", in M.R.E., Documentos de Politica Externa, vol. Iv, 1969-1970, pp. 193-195.

${ }^{259} \mathrm{E} . \mathrm{g}$., Brazil's cautious support, in 1970, of opening the Treaty on Nuclear Non-armament of the Sea Beds to General signing; M.R.E., Documentos de Politica Externa, vol. vir, 1973, p. 261.

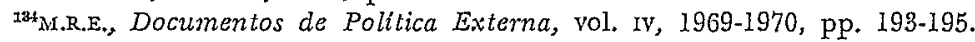

${ }^{135} \mathrm{Cf}$. The Presidency of the Federative Republic of Brazil, O Programa Nu. clear Brasileiro, Brasilia, 1977, pp. 21-22, and cf. pp. 27-51; cf. also, "O Programa Nuclear Brasileiro, um Dossie Histórico", M.R.E., Resenha de Política Exterior do Brasil, No 12, January-March 1977, pp. 9-16, and pp. 27-28 for recent data; cf. also, e.g., the study by J. E. Greno Velasco, "El Acuerdo Brasil-RFA Y el Principio de No Proliferación Nucleax", 154 Revista de Politica Internacional - Madrid (1977), pp. 113-144. On the Treaty of Tlatelolco, cf. the useful collection of documents in A. Garcia Robles, El Tratado de Tlatelolco, México D. F., El Colegio de México, 1967, pp. 3-339; cf. also texto in: Boletim da Sociedade Brasileira de Direito Internacional (1967) No 45/46, pp. 163.175; and, more recently, H. Gross Espiell, Proscrição de Armas Nucleares na America Latina", I Direito Nuclear (1979) No 2, pp. 45-51. For Brazil's participation in negotiations for concluding the 1971 Treaty Prohibiting Placement of Nuclear and Other Weapons of Mass Destruction on the Ocean Floors and Subsoil, cf. B. Ramberg, The Seabed Arms Control Negotiation: A Study of Multilateral Arms Control Conference Diplomacy, Denver, University of Denver, 1978, pp. 30, 32, 34, 39, 63, 66-69, 77, 81-82, 88 and 91, and cf. also, pp. 15, 107-109 and $114-115$. 
șionalmente hasta entonces ${ }^{138}$. EI memorándum brasileño sugiere además que el Consejo de Seguridad establezca un comité ad hoc con mandatos lo más amplios posible para resolver pacíficamente las disputas, en las cuales las partes en litigio puedan participar en negociaciones junto con otras delegaciones (posiblemente cuatro) citadas para el efecto por el Consejo, por sugestión de las partes. El objetivo de este procedimiento sería el de armonizar los puntos de vista de las partes.137. Desde ese tiempo, Brasil ha sido un defensor constante y fiel del fortalecimiento del sistema de la onu para preservar la paz y la seguridad internacionales (cf. supra)

\section{LAS POSICIONES del BRASIL EN LA CONFERENCIA DE LA ONU SObre Comercio y Desarrollo (UnCTAD)}

Brasil ha hecho sentir su presencia desde el comienzo de los trabajos preparatorios que culminaron en la UNCTAD i en Ginebra, desde el 13 de marzo al 16 de junio de 1964. Un producto significativo de ese trabajo fue la Declaración Conjunta de 75 países en desarrollo, en cuya redacción particiṕó el Brasil, presentado a la Asamblea General el 2 de noviembre de 1963 y que abogaba por una "nueva división internacional del trabajo, si es necesario con nuevos patrones de producción y comercio"138. Tratamiento separado requeriría una revisión de las posiciones del Brasil adoptadas ante el Consejo de Comercio y Desarrollo y las diversas comisiones de la UNCTAD; en el siguiente examen, este trabajo se limita a enfocar las principales declaraciones emitidas por la delegación brasileña en las sesiones plenarias de las reuniones de la UNCTAD ${ }^{139}$.

En la UNCTAD I (Ginebra, sesión plenaria del 24 de marzo de

${ }^{180}$ Carlos Calero Rodrigues, "As Nações Unidas como Instrumento de Ação Polftica na Solução Pacífica das Tensões Internacionais", 32 Revista Brasileira de Estudos Politicos (1971), p. 42; Brazil's observations can be found in U.N. document $\mathrm{A} / 7922$, of 1970 , and come from the initial suggestion of Ambassador Araujo Castro.

${ }^{13} I$ ib.d., p. 43.

${ }^{185}$ UNCTAD - United Nations Conference on Trade and Development, Basic Documents, uN Publ. Sales No 66.r.14. And cf. also, the Conference report pre. pared by its' secretary, Raúl Prebisch, Towards a New Trade Policy for Development, ONU, document $\mathrm{E} / \mathrm{CONF} .46 / 3.141,1964$.

${ }^{100}$ For some of the Brazilian proposals and positions on the internai work of unCTAD (up to late 1970), cf., e.g., documents: TD/B/SG.1/L.7, TD/B/L.14, and Add. I-3, TD/B/WP.1/SR.1-18, TD/B/L.74, TD/B/L.84-85,TD/B/L.80-82, TD/B/L.71/Rev, 1, TD/ B/SG.5/L.2, тD/B/L.97-99, тD/B/L.130, Official Records (23rd Session) supl. $14-$ pp. 86 and 89, $\mathrm{TD} / \mathrm{B} / \mathrm{L} .157 /$ Rev. 1, TD/B/L.I47-149, TD/B/L.153, $\mathrm{TD} / \mathrm{B} / \mathrm{L} .167$ and Corr. I, TD/B (VIII)/sc.2/L.2 and Add. I, TD/B/(vIr)/sc.2/L.5 and Corr. 1 and L.6, $\mathrm{TD} / \mathrm{B} / 189 /$ Rev. I, TD/B/188/Rev. 1, TD/B. (IX)/Sc.1/L.4, TD/B (IX)/ SC.1/L.I, TD/ B/L.181, TD/B/L.183, TD/B/SR.238, TD/B/L.208, TD/B/L.206/Rev. I, TD/B/L.233/Rev. $1, \mathrm{TD} / \mathrm{B} / \mathrm{L} .233 /$ Rev. 1, TD/B $(\mathrm{x}) / \mathrm{sc} .1 / \mathrm{L} . \mathrm{TD} / \mathrm{B} / \mathrm{L} \cdot 235, \mathrm{TD} / \mathrm{B} / \mathrm{C} .1 / \mathrm{L}, 10, \mathrm{TD} / \mathrm{B} .(\mathrm{x}) / \mathrm{sc} . \mathrm{I} /$ L.8. 
1964), el jefe de la delegación brasileña expuso la posición del Brasil dentro de un marco de precedentes significativos (p. ej. la Conferencia de La Habana de 1947, GATT en 1948 y la revisión de 1954, la Conferencia de El Cairo en 1962, la xvir Asamblea General, las sesiones del Comité Preparatorio de la actual Conferencia en la xvinx Asamblea General). En su discurso denunciando el deterioro de los términos de intercambio en comercio internacional, el Ministro brasileño de Relaciones Exteriores añadió que, la UNGTAD I no era un evento aislado, "más bien un momento en un proceso histórico", destinado a transformar el comercio internacional en un instrumento para promover el bienestar entre las naciones y el desarrollo de los países más pobres. Finalmente, Araujo Castro lamentó la resistencia a tal iniciativa, ya demostrada por los países desarrollados en la Xvirr Asamblea General ${ }^{140}$.

Cuatro años más tarde, en la II UNGTAD, (Nueva Delhi, 28 de marzo de 1968), al considerar los diversos temas bajo examen en la Conferencia (materias primas, preferencias, financiamiento, carga marítima y transferencia de tecnología), el jefe de la delegación brasileña concluyó, en un discurso muy crítico y pesimista, que la Conferencia no estaba cumpliendo con las expectativas y estaba destinada a fallar, dada la incapacidad de los países desarrolldos para aceptar ciertos planos propuestos. Para él, la II unctad fue una "frustración y desencanto", lo que, sin embargo, no destruyó a la UNCTAD como un órgano permanente. Por ejemplo, así como la UNGTAD I había visto la emergencia del Grupo de los 77, la UNCTAD II "consolidó la unidad del Grupo". Al mismo tiempo, Azeredo da Silveira hizo notar que la función de la cooperación económica internacional en el desarrollo depende de tendencias político-económicas que escapan al control de los países en desarrollo. Así, para el embajador brasileño, los países en desarrollo deberían acostumbrarse a confiar más y más en sus esfuerzos individuales y en la cooperación entre ellos, dado que la "comunidad internacional todavía no está preparada para aceptar las implicaciones prácticas de las responsabilidades conjuntas por el desarrollo"141.

Todavía dentro de la II UNCTAD, en un combativo discurso pronunciado el 5 de febrero de 1968, el Ministro brasileño de Relaciones Exteriores alegó que el comercio internacional era "el área que mostraba la mayor discriminación, que estaba aumentando desde hacfa mucho tiempo". Recordó el ejemplo del GATT como "una

${ }^{1+0}$ M.R.E., Speech by the Minister of State of Foreign Relations of Brazil, J. A. de Araujo Castro, Chefe de Delegação, at I UNGTAD (4th plenary session, March 24, 1964), 4 pp. (internal circulation).

${ }^{I+1}$ M.R.E., Closing speech by the Head of the Brazilian Delegation, Ambassador A. F. Azeredo da Silveira, II UNGTAD (New Delhi, March 28, 1968), 8 pp. (internal circulation). Azeredo da Silveira actually suggested the creation of a permament organ that would perform the same function for developing countries as the OECD does for the developed countries, ibid., p. 6. 
institución limitada a propósito a los logros que beneficiaban a aquellos países que ya tenían gran parte del comercio internacional, mucho más que aquellos que veían año a año disminuir su per queña participación en el comercio mundial"142. Magalhaes Pinto, hablando ante el plenario de la II UNCTAD, sugirió la "aprobación de normas para la negociación de un sistema de preferencias para exportaciones manufacturadas de los patses subdesarrollados a países desarrollados", y la normalización del comercio mundial de productos, (garantizando el libre acceso a los mercados mundiales para exportaciones de materias primas, vía el rechazo de medidas proteccionistas de parte de los países ricos) ${ }^{143}$.

Al finalizar la sesión de Nueva Delhi, la delegación brasileñá preparó una serie de informes presentando. "subsidios para la acción futura del Brasil en la UNCTAD". Los objetivos fundamentales del Brasil pueden resumirse como "la máxima obtención de posibles ventajas concretas en la UNCTAD", en consolidar la "unidad de acción" de los países en desarrollo y el "reequipamiento funcional de la UNCTAD y su transformación en un órgano operacional"144. Al nivel sustantivo, se daría atención prioritaria a las futuras negociaciones sobre preferencias generales y no discriminatorias ${ }^{145}$. A nivel de Comisión en la II UNCTAD, la delegación brasileña deploró que los países desarrollados no hubiesen seguido los principios adoptados en la I UNCTAD y defendido "una reducción general y una eliminación progresiva de las medidas proteccionistas que afectaban a productos de interés para los países en desarrollo"146. Así, la delegación brasileña externalizó su preocupación con la continuación de la discriminación existente sobre los planes preferenciales y con la posibilidad de su proliferación en diferentes regiones del mundo, contribuyendo, por consiguiente, a la "Iormación o conso: lidación de esferas de influencia que en cierto modo son reminiscentes de anacrónicos conceptos geopolíticos" e incompatibles con la filosofía básica de la UNCTAD ${ }^{14 T}$.

En la III uNCTAd (Santiago, 17 de abril de 1972), un vocero de la delegación brasileña nuevamente atacó a los países desarrollados, que no siempre muestran comprensión acerca de que "la elimina.

1.2"Discurso proferido pelo Ministro Magalhães Pinto Perante o Plenario da II UNCTAD, em Nova Delhi, em 5/2/1968", in Gestao Magalhães Pinto no Minis: terio das Relações Exteriores - Relatorio Final, M.R.E., October 1969, pp. 52_54.

1s3rid., pp. 54-56; The Brazilian minister showed apprehension about the international maritime transportation situation and international financing.

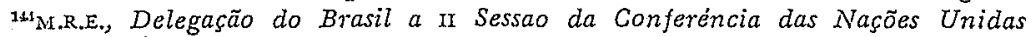
para o Comercio e Desenvolvimento, vol. I: Relatorios, 1968, pp. 53-54.

${ }^{145}$ Ibid, p. 55: the document focuses on, inter alia, intermediate products, financing, and maritime transportation.

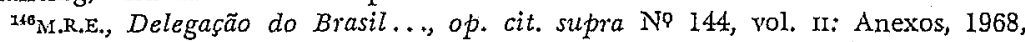
annexes $\mathrm{L}$ and. $v$, items 9 (d), respectively.

${ }^{1{ }^{\prime}}$ Tbid, , vol. $\mathrm{I}$, annex $\mathrm{v}$, item 9 (d) .. 
ción de las disparidades económicas es la responsabilidad de la comunidad internacional como un todo" (la estrategia "global" para el desarrollo). Alvares Maciel ilustró esto con ejemplos monetarios y comerciales y deploró que el SGP no había llegado a cumplir las expectativas de los países en desarrollo. El embajador brasileño, al advertir que no puede haber seguridad política colectiva sin seguridad económica (implementación gradual de una división internacional del trabajo, dirigida hacia el desarrollo), identificó como algunas de las principales razones para esta visión pesimista "las tendencias hacia una mayor verticalización del comercio internacional, un aumento en márgenes de discriminación de tarifas, y un mayor grado de proteccionismo" (situación que puede empeorar). Alvares Maciel afirmó categóricamente que la delegación brasileña rechazaría cualquier "intento de convertir a la UNCTAD en una organización restringida a funciones redistributivas dentro del contexto de la UNCTAD de estructuras existentes; era muy necesaria la reforma institucional de la UNCTAD ${ }^{148}$.

En la unctad Iv (Nairobi, mayo 6 de 1976), el jefe de la delegación brasileña se refirió a un nuevo movimiento destinado a beneficiar un nuevo orden económico internacional (emergiendo de series de acuerdos internacionales que estaban por finalizar en diversas áreas de las relaciones económicas internacionales), e hizo referencia a la necesidad de una completa revisión de las relaciones comerciales Norte-Sur (propuesta por el Ministro de Relaciones Exteriores del Brasil, Azeredo da Silveira, en la vII Sesión Especial de la Asamblea General de la oNu). Aún más, se refirió a los códigos de conducta para las multinacionales, en proceso de negociación, y a la necesidad de una repartición más equitativa de la riqueza mundial entre los países en desarrollo. Alvares Maciel ponderó que "los países desarrollados han enfrentado las negociaciones con los países en desarrollo sin una perspectiva estricta, ortodoxa. Han tenido un enfoque caso a caso, producto por producto $(\ldots)$. Un tratamiento más favorable y diferencial no puede ser una excepción caso por caso a las reglas del juego: debe ser una regla en sț misma, aplicable a las adecuadas áreas de negociación"149. Más recientemente, en la v unctad (Manila, mayo 8 de 1979), el jefe de la delegación brasileña comenzó su exposición reafirmando la solidaridad y el origen histórico que une al Brasil con el Grupo de los 77, un grupo que el Brasil ve como "un instrumento de coope-

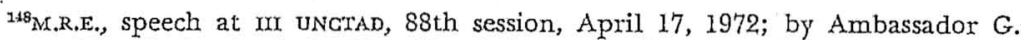
Alvares Maciel, head of the Brazilian Mission to the OAS and Deputy Fead of the Delegation from Brazil, 3 pp. (internal circulation). Cf. also, M.R.E., Docum mentos de Politica Externa, vol. vx, 1972, pp. 119-124.

${ }^{149}$ M.R.E., speech by the Head of the Brazilian Delegation, Ambassador G. AIvares Maciel, IV UNGTAD, Nairobi, $5 / 6 / 1976,11 \mathrm{pp}$. (internal circulation). Cf. also, Proceedings of the IV UNCTAD (Nairobi, 1976), vol. II: Summaries of Statements by Heads of Delegation..., U.N. doc. TD/218 (vol. II), Pp. 14.15.
} 
ración y negociación". En cuanto a acuerdos sobre un fondo común de productos, el embajador brasileño reafirmó el. interés de su país en la negociación y conclusión de acuerdos dentro del programa integrado, como también del código de transferencia de tecnología (facilitando tales transferencias y controlando prácticas abusivas en contratos de transferencia). Alvares Maciel además expresó sư preocupación por la posibilidad de que fuesen tomadas medidas y decisiones unilaterales por los países industrializados y criticó "el nuevo orden proteccionista en los países desarrollados, del cual los países en desarrollo son siempre las víctimas principales"150

Un analista de las dos primeras UNGTAD destaca dos factores relevantes a la posición del Brasil. Primero, el propósito de un alineamiento más sólido entre el Brasil y el grupo afroasiático en la I UNCTAD (Ginebra, 1964) y un distanciamiento paralelo de los países industrializados, deseado por los partidarios de una "política exterior independiente", que fue imposible de ser llevado a cabo debido a los cambios internos acaecidos en Brasil en marzo y abril de 1964; como consecuencia, Brasil adoptó una posición más cauta y conciliadora con los países occidentales ${ }^{151}$. En la II UNGTAd (Nueva Delhi, 1968) Brasil intentó acercarse a los países afroasiáticos, y Azeredo da Silveira fue, de nuevo, elegido presidente del Grupo de los 77 para la fase final de la Conferencia; fue entonces que pronunció uno de los discursos más pesimistas con respecto al trabajo de la unctad (cf. supra), un discurso con el cual, sin embargo, no estuvo dè acuerdo otro grupo de los 77 estados miembros. Sucedió que la posición del Brasil como un país semi-industrializado condujo sus intereses hacia una dirección que no siempre coincidía con aquellas de países en diversas etapas de desarrollo ${ }^{152}$.

Este hecho no es sorprendente si, además, se considera la frágil unidad del Grupo de los 77 como una institucionalización de algunos de los ideales de los países menos desarrollados ${ }^{153}$. La falta de cohesión del Grupo se hizo más evidente en la III UNCTAD (Santiago, 1972), con algunas de las luchas de los países más pobres para garantizarse a sí mismos la mayor participación posible en la distribución de favores y privilegios tarifarios, y el establecimiento de criterios para determinar los 25 países más pobres, con el propósito de obtener concesiones y privilegios (que también buscaban

\footnotetext{
${ }^{180}$ M.R.E., speech by the Head of the Brazilian Delegation, Ambassador G. Alvares Maciel, at the $\mathrm{v}$ Unctad Meeting, Manila, May 8, 1979, $6 \mathrm{pp}$. (internal circulation) .

${ }^{1 a t} W$. A. Selcher, The Afro-Asian Dimension of Brazilian Foreign Policy, Gainesville, University Presses of Florida, 1974, pp. 199.202.

162Ibid., pp. 203-208; in addition to competition over exporting certain products and raw materials. Cf. also, B. Gosovic, "UNCTAD: North-South Encouter" No 568 International. Conciliation (1968), pp. 19-20.

Jasornal do Brasil, October 26, 1971, 1st caderno, p. 22.
} 
otros países) ${ }^{154}$. Después de la IV UNCTAD (Nairobi, 1976), fue considerada la posibilidad de ciertas adaptaciones en el sistema de negociación (Grupo de 77 países en desarrollo, Grupo B de países desarrollados con economías de mercado y grupo $\mathrm{D}$ de países socialistas de Europa del Este); si se formara un grupo intermedio entre el Grupo de los 77 y el Grupo B, Brasil habría sido un fuerte candidato para él155. Naturalmente, continúan existiendo diferencias económicas entre los estados en el núcleo del Grupo de los 77, como también en el grupo B, y hay medidas que benefician al Sur más directamente que también puedan interesar al Norte ${ }^{156}$.

Así, no es sorprendente que las declaraciones del Brasil desde la IV UNCTAD hayan sido de diferente tenor que, por ejemplo, en la II UNCTAD. Consciente de su peso, Brasil parece haber visto en forma más positiva los esfuerzos para el diálogo de la UNCTAD, y ha optado por una línea de negociación más flexible (incluso dentro de los países desarrollados), evitando confrontaciones. Un ex Canciller brasileño hizo notar recientemente que el Brasil, como país intermedio y habiendo acumulado experiencia desde la UNCTAD I en 1964, "se siente que está en una posición particular para entender igualmente el razonamiento de los países industriales, como también el de los países desarrollados"157.

\section{LAS POSICIONES DEL BRASIL EN CONFERENCIAS INTERNACIONALES}

\section{III Conferencia de la onu sobre Derecho del Mar (1974-1980).}

Sería muy difícil encontrar un área entre el vasto corpus de la ley

${ }^{15} \mathrm{~A}$. A. Cançado Trindade, Considerações Acerca do Relacionamento Entre $O$ Direito Internacional e o Direito Económico, Belo Horizonte, Fundação Brasileira de Direito Económico, 1972, pp. 55 and 57.

${ }^{180} \mathrm{Ch}$. R. Evans, op. cit. supra № 32 , pp. 241-244. Cf. previously, on a possible group of "intermediate level" developing countries, M. A. Ozorio de Almeida, "O Mundo Subdesenvolvido Perante as Sociedades Pos-Industriais", 32 Revista Brasileira de Estudos Politicos (1971), pp. 102-103.

${ }^{166} \mathrm{~T}$. Smith, "Changing Configurations of Power in North_South Relations Since 1945", 31 International Organization (1977), pp. 1-27.

${ }^{15 ̄}$ A. F. Azeredo da Silveira, "A Política Externa e a Ação de Itamaraty", Valores e Rumos do Mundo Ocidental (II Painel de Assuntos Internacionais da Comissão de Relações Exteriores da Camara dos Deputados), Brasilia, 1978, p. 498. - In addressing the III Meeting of Foreign Relations Ministers of the Group of 77 (New York, 1979), present Chancellor Saraiva Guerreiro showed a certain concern in keeping the Group united, and called out for the delegates present to "guide our solidarity toward concrete objectives that can clearly be attained". Brazilian Mission to the United Nations, "Statcment by Ambassador R. Saraiva Guerreiro, Minister of External Relations of Brazil, to the III Meeting of Ministers of Foreign Affairs of the Group of 77 ", N. Y., September 28, 1979, pp. 4-5 (mimeographed, internal circulation). - For an historical summary of the Group of 77 , cf. Jornal do Brasil, October 26, 1971, 1st caderno, p. 22. 
internacional contemporánea, en la cual hayan contribuido los países latinoamericanos tan marcadamente como en el Derecho del Mar: Los diversos reclamos de los estados latinoamericanos, ya sea con respecto a la plataforma continental, al mar territorial, al mar patrimonial, a la zona económica exclusiva o a las zonas nacionales de pesca -todas las cuales tienden a reconocer derechos prioritarios, favoreciendo las poblaciones costeras y el desarrollo socioeconómico de los estados costeros y de sus habitantes-, han aportado innegablemente, genuinas innovaciones al derecho internacional del mari58.

En la Inr Conferencia del Derecho del Mar, actualmente en proceso, hay indicaciones de que se llegará a un acuerdo del Derecho del Mar futuro, excepto en el tema de la explotación de los recursos de los fondos marinos, que continúa hasta hoy siendo la gran impasse de la Conferencia ${ }^{159}$. En cuanto a la posición del Brasil en la Conferencia, la delegación ha mantenido ciertos puntos de vista básicos desde la iniciación de la Conferencia hasta ahora. Dos de las principales posiciones brasileñas se refieren al establecimiento de un límite de 200 millas dentro de las cuales un estado costero puede exigir ciertos derechos, y la creación de mecanismos previendo la participación de los países en desarrolio en la explotación de recursos minerales en los fondos marinos, más allá de sus jurisdicciones nacionales ${ }^{160}$.

Con respecto a la extensión del mar territorial ${ }^{161}$, la posición del

${ }^{165 F}$. V. Garcia_Amador; "A Contribuição da America Latina para o Desenrolvimento do Direito do Mar", Curso de Direito Intemacional, Rio de Jainero, Fundação Getulio Vargas, 1977, pp. 93-130; V. Marotta Rangel, "A Proxima Conferéncia sobre Direito do Mar e seus Antecedentes", Problemas Brasileiros (September 1972), pp. 6-16; K. Hjertonsson, The New Law of the Sea - Influence of the Latin American States on Recent Developments of the Law of the Sea, Leiden/Stockholm, Sijthoff/Norstedts, 1973, pp. 19-179.

${ }^{17 n}$ B. H. Oxman, "The Third United Nations Conference on the Law of the Sea: the Eighth Session (1979) ", 74 American Joutnal of International Law (1980), pp. I-47; B. H. Oxman, "The Third United Nations Conference on the Law of the Sea; the Seventh Session (I97S)", 73 A.J.L.L. (1979) p. Iss.; B. H. Oxman, "The Third United Nations Conference on the Law of the Sea: the 1977 New York Session", 72 A.J.L.L. (1978), pp. 57-83; B. H. Oxman, "The Third United Nations Conference on the Law of the Sea: the 1976 New York Sessions", 71 A.J.I.L. (1977), pp. 247-269; J. R. Stevenson and B. H. Oxman, "The Third u.N. Conference on the Law of the Sea: the 1975 Geneva Sessions", 69 A.J.I.L. (1975), pp. 763.797; J. R. Stevenson and B. H. Oxman, "The Third U.N. Conference on the Law of the Sea: the 1974 Caracas Session", 69 A.J.X.L. (1975) pp. I-30; K. O. Rattray, "III Conferéncia das Nações Unidas sobre Direito do Mar - Reflexöes sobre Caracas, Perspectivas para Genebra", Curso de Direito International, Rio de Janeiro, Fundação Getulio Vargas, 1977, pp. 55-92.

${ }^{100}$ M.R.E., Resenha de Politica Exterior do Brasil, N9 12, January-March 1977, p. 28.

arror general studies, cf e.g.: Marinha do Brasil, Mar Territorial; Brasilia CEGRAF, s/d, tomes I-II; (Multiple authors); Estuddos do Mar Brasileiro; Rio 
Brasil è las dos primeras Conferencias (1958 y. 1960) fue cautelosa y moderada, dado que la principal área de controversia se refería precisamente a los límites del mar territorial y a la jurisdicción. sobre zonas de pesca ${ }^{162}$. En efecto, el mar territorial de las $200 \mathrm{mi}-$ llas sólo fue propuesto en el Congreso brasileño en 1967, en tanto Itamaraty mantenía su posición cauta en vista de las convenciones de Ginebra sobre Derecho del Mar (1958), y se debatió a fines de 1969, con la aprobación de la extensión por parte del Congreso en mayo de $1970^{163}$.

Cuando comenzó el trabajo en la IIr Conferencia sobre el Derecho del Mar, la delegación brasileña, al insistir en el límite de las 200 millas, recalcó el interés por un "desarrollo económico acelerado" que no perjudicase los legítimos intereses de la asíllamada comunidad internacional. Los comunicados brasileños hacen referencia, inter alia, a la utilización de los recursos oceánicos, a la supervisión de la investigación científica y a la conservación de la ecología y medio ambiente marino ${ }^{164}$. Pero, como observó un analista recientemente, en tanto que el Brasil continuaba reafirmando el derecho al límite de las 200 millas dentro de un punto de vista territorialista, también estaba consciente de la creciente aceptación del concepto de mar patrimonial (zona económica) ${ }^{165}$; una posición brasileña aparentemente más flexible, que no rechazaba la posibilidad de adaptación, se hizo más aparente en la sesión de Garacas (1974) de la III Conferencia, como también en la tercera y cuarta sesiones (1975-1976) de la Conferencia ${ }^{166}$.

de Janeiro, Ed. Renes, 1972, pp. 9-209; V. Marotta Rangel, Natureza Juridica e Delimitação do Mar Territorial, 2nd ed. rev., São Paulo, Ed. Rev. Trib., 1970; pp. 17-22.

${ }^{160}$ M. A. Morris. International Politics and the Sea: the Case of Brazil, Boulder/Col., Westview, 1979, pp. 65-68 and 68-86. - For Brazil's previous positions upon convocation in 1956 of the $\mathrm{Y}$ U.N. Conference on the Law of the Seas, 1958, cf. Gilberto Amado, "O Brasil e o Direito do Mar", 169 Revista Forense (1957) pp. 9-15.

${ }^{103}$ Cf. M. A. Morris, op. cit. supra, $N^{\circ} 162$, pp. $31-33$ and $35-44$, for a detailed description.

${ }^{10}$ Cf., e.g., statement by the Brazilian delegate, in U.N. Third United Nations Conference on the Law of the Sea, Official Records, vol. I (Summary Records of Meetings, N. Y./Caracas, 1973-1974), document A/CONF.62/sk.1-51, pp. 60-61. ${ }^{16} \mathrm{Cf} .:$ W. C. Extavour, The Exclusitue Economic Zone - A Study of the Evolution and Progressive Development of the International Law of the Sea, Geneve/Leiden, I.U.H.E.r./Sijthoff, 1979, pp. 1-369; G. Marston, "The Development of the Larv of the Sea with Special Reference to the Exclusive Economic Zo. ne", 3 Ulfljotur - Reykjavik (1974), pp. 297-307; A. A. Cançado Trindade, "Direito e Relações Internacionais: Resenha Bibliográfica Seletiva", 5 Relaçôes Internacionais - Brasilia (1980), pp. 87.89 (part v: "Desenvolvimentos no Direito do Mar Contemporáneo").

${ }^{160}$ M. A. Morris, op. cit. supra No 162, pp. 141-142 and 145-146: for the author, however, Brazilian reactions to the growing popularity of the economic zone concept reflect "modifications in the negotiation strategy", rather than any fundamental political change (ibid., p. 150). 
Actualmente (junio 1980) hay indicaciones de que Brasil permitiría revisar su posición, retornando al tradicional límite territorial de 12 millas, pero conservando sus derechos para explotar: rècursos económicos dentro de su zona económica de 200 millas ${ }^{167}$. Hay algunos que sugieren que, si se implementa ahora la extensión del mar territorial, el énfasis en las razones político-estratégicas y. de seguridad es desplazado por razones económicas ${ }^{168}$.

La posición del Brasil ha sido clara y firme en lo concerniente a las aguas dentro de la jurisdicción nacional: sus esfuerzos se han dirigido" hacia "el reforzamiento" y ampliación de los derechos de los estados costeros sobre la zona marítima contigua a sus costas hasta una distancia de 200 millas náuticas sobre el suelo y subsuelo correspondientes y más allá de la plataforma continental"160. Itamaraty se ha opuesto, por lo tanto, a los esfuerzos de los poderes marítimos para categorizar la zona económica como parte de los espacios oceánicos donde los estados costeros ejercerían un limitado número de derechos específicos a través de concesiones por parte de la comunidad internacional"170.

Si, por una parte, Brasil ha difundido los derechos de los estados costeros sobre las aguas dentro de su jurisdicción nacional (zona maritima contigua a sus costas - supra), por otra parte, ha sido partidario de aplicar un sólido régimen al área de los suelos marinos situados más allá de las jurisdicciones nacionales. Como ya se mencionó, este es un punto que ha polarizado los debates en la III Gonferencia del. Derecho del Mar y ha probado ser uno de los más difíciles para lograr consenso (supra).

Ya en 1970, en Ia Asamblea General, el Embajador Ramiro Saraiva Guerreiro apoyó el proyecto de formulación de un equitativo régimen internacional para los suelos marinos y oceánicositi. En la declaración del delegado brasileño, el núcleo del proyecto era el principio básico de que "todos los suelos oceánicos fuera de los límites de jurisdicción nacional son herencia común de la humanidad"; este principio tiene dos aspectos principales: "él área no será un objeto de apropiación ni por los estados ni por personas -físi-

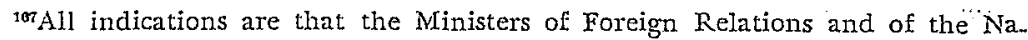
vy are in agreement on this point: "Mar Brasileiro Vai Ser de Doze Milhas", Correio Brasiliense, Brasilia, July 5, 1980, p. 10 . On the emerging concept of an exclusive economic zone, cf. bibliography in No 165 supra; cf. also, v.N. document A/CONF.02/WP.10/Rev. 2, of April 11, 1980,. Third U.N. Conference on the Law of the Sea: Informal Composite Negotiating Tex - Revision 2, pp. 44-54 (articles 55-75).

${ }^{109 \mathrm{MI} . ~ A . ~ M o r r i s, ~ o p . ~ c i l . ~ s u p r a ~ N o ~ 162, ~ p p . ~} 45.46$.

${ }^{109}$ Relatorio do Ministerio das Relações Exteriores - 1976, M.R.E., 1979, p. 129.

${ }^{270}$ Ibid., p. 129. And cf., e.g., Government of Iceland, The Evolving Limit of Coastal Jurisdiction, Reykjavik, Prent-smiojan Ed., 1974, pp. 7-128.

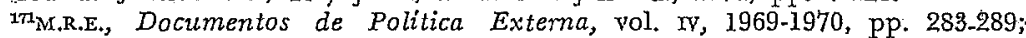
M.R.E., Doc: Pol. Ext., vol. v, 1971, pp. 34-39, and cf. pp. 207-212. Cf. also M.k.E., Doc. Pol. Ext.; Yol. YII, 1973, pp.149-150 and 4I-cl42. 
cas o legales- y, por otra parte, todos los estados tienen el derecho de participar en su administración y de recibir una parte justa de Ios beneficios derivados de la explotación de actividades que puedan ser llevadas a cabo"172.

EI Comité sobre los Fondos Marinos, creado en la onv en 1968 y. que tres años después ya contaba con 91 miembros, fue responsable de gran parte del trabajo preparatorio (1971-73) para la II Conferencia del Derecho del $\mathrm{Mar}^{-173}$. Los estados Iatinoamericanos pidieron amplios poderes para una autoridad internacional sobre los suelos marinos y oceánicos, y Brasil defendió tal régimen, pero con más flexibilidadit4. EI embajador Saraiva Guerreiro advirtió en el Gomité que deberían tomarse en cuenta dos principios básicos: flexibilidad y universalidad ${ }^{175}$. Como se sintetiza en el Informe de Itamaraty, de 1976, "entre el principio de libre explotación de los fondos marinos, propiciado por los países industrializados, y el control de esta explotación por una autoridad internacional, apoyada por los países en desarrollo, se busca una fórmula intermedia, capaz de conseguir apoyo general"176. Ahora que el trabajo de la III. Conferencia éstá muy avanzado, el simple hecho de que numerosos estados participantes hayan perseverado en la búsqueda colectiya de un régimen oceánico, a pesar de sus intereses diversos y conflictivos, constituye un considerable progreso en la conducta de la diplomacia contemporánea multinacional.

\section{2: Conferencia de Las Naciones Unidas para el Medio Ambiente (Estocolmo, 1972) y algunos desarrollos posteriores.}

El período desde 1970 a 1972 atestigua los intensos esfuerzos diplomáticos de Itamaraty para formular y fortalecer la posición del Brasil de que la política sobre medio ambiente de un país en desarro110 debe ser formulada por éste, incluso si choca con posiciones defendidas por los países desarrollados ${ }^{177}$. Ya en agosto de 1970 , fuentes de Itamaraty expresaron que no era adecuado que los países en desarrollo bajaran su tasa de industrialización para mante-

172Ibid., p. 284.

${ }^{173}$ It is worth remembering, e.g., relevant U.N. resolution $2.574 \mathrm{D}$ (xxrv) of 1969, declaring a moratorium on exploitation of that sea bed area outside of national jurisdiction, pending an international regime for that area (not subjet to superpower veto); such a "moratorium resolution" was adopted on December 15, 1969, despite "intense opposition" from the developed countries: M. A. Morris, op. cit. supra NQ 162, pp. 127 and 117. Brazil supported the resolution early on (ibid., pp. 128-139).

${ }^{174}$ Cf. ibid., pp. 139-140 and cf. oNU, document A/Ac.138/49, cit. in ibid. p. 139.

${ }^{2 \pi}$ M.R.E., Documentos de Politica Externa, vol. Iv, 1969-1970, p. 286. Naturally, the international zone would be "reserved exclusively for peaceful ends"; ibid., p. 285.

${ }^{276}$ Relatorio do Ministerio das Relações Exteriores - 1976, M.R.E., 1979, p. 128.

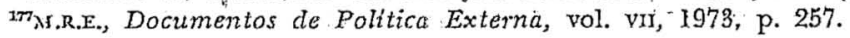


ner la atmósfera sin contaminación, especificamente porque la principal responsabilidad por crear y resolver el problema cae sobre los países que ya están industrializados ${ }^{178}$. Así, el principal peso para poner remedio al deterioro ecológico en un nivel global caería sobre quienes tienen la mayor responsabilidad frente a la contaminación: los países desarrollados. Al mismo tiempo, los países industrializados deberían considerar el desarrollo económico como el medio más adecuado para resolver problemas de cambio y contaminación del medio ambiente, hasta un cierto grado conectado con las condiciones de pobreza prevalecientes. Para esos países industrializădos, las amenazas de desempleo y pobreza que se derivan del subdesarrollo eran riesgos más importantes que aquellas de la contaminación, típicas de las sociedades post-industriales más prós$\operatorname{peras}^{17 \theta}$.

Fue en este sentido que la posición del Brasil fue presentada en Estocolmo. En la sesión inaugural (6 de junio de 1972), el jefe de la delegación brasileña, el ministro José da Costa Cavalcanti expuso la posición de Brasil, que puede resumirse así:

"Puesto que fue precisamente el crecimiento económico el que permitió que los países desarrollados progresaran en la eliminación de la pobreza, y dieran por tanto alta prioridad a la protección del medio ambiente, aquellos países que todavía no han alcanzado el nivel mínimo para satisfacer las necesidades esenciales deberian preocuparse ante todo de mejorar sus patrones de vida. Aún más, el deterioro ambiental va más allá de la contaminación industrial, porque el subdesarrollo trąe formas de degradación en zonas rurales y urbanas ( $p$. ej. contaminantes biodegradables). Por tanto, tales problemas deben ser debatidos en conexión con el desarrollo económico, incluyendo temas de materias primas $y$ productos primarios. En conclusión, los temas ambientales deberían ser de responsabilidad nacional y caerían dentro de la esfera de la permanente soberanía de un estado frente a sus recursos naturales"180.

$\mathrm{Si}$, por una parte, Brasil mantuvo que los problemas ambientales eran una preocupación local y el punto de partida para resolverlos debería ser la ejecución de programas nacionales ${ }^{181}$, por la otra, Brasil admitió que al ejercer una soberanía permanente sobre los recursos nacionales cada paf́s, de acuerdo a sus propias necesidades y prioridades, debería explotar sus propios recursos, de manera tal de evitar apreciables efectos deletéreos en otros paises ${ }^{182}$.

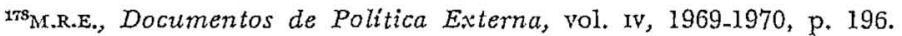

${ }^{179}$ M.R.E., Documentos de Politica Externa, vol. vi, 1972, p. 111.

${ }^{180} \mathrm{Cf}$. entire text of the statement, reproduced in M.R.E., Documentos de Politica Externa, vol. vi, 1972, pp. 167-172.

18u Estado de São Paulo, June 4, 1972, 8th caderno, p. 1.

xofornal do Brasil, furie 7, 1972, 1st caderno, p. S. 
Fortaleció la posición brasileña la intervención del Secretario General de la OEA, Galo Plaza, al efecto que América Latina no podía someterse a un riguroso control ecológico en detrimento de su desarrollo183. La delegación china fue más allá, al condenar expresamente a los países desarrollados por el deterioro de los recursos de la tierra ${ }^{184}$. La impasse entre ricos y pobres en la Conferencia de Éstocolmo se hizo evidente en los esfuerzos de políticas coloniales que nunca respetaron los recursos naturales de los países explotados ${ }^{185}$.

Con respecto a la posición brasileña, desde el primer día de la Conferencia, Brasil confrontó una enmienda presentada por Argentina, en la cual a cualquier estado podría serle requerido proporcionar la información, por la parte interesada, sobre proyectos naturales que pudieran tener repercusiones en el medio ambiente ecoIógico de otros países. Brasil argumentó que un estado podría rehusar contribuir a un sistema tal de información y consulta previa cada vez que percibiera que ella significaría un riesgo para su seguridad y desarrollo económico; en compensación, Brasil ofreció indemnizar a cualquier país cuando sus actividades causaran daño én otros territorios ${ }^{1 S 6}$.

Uruguay superó la impasse Brasil-Argentina cuando propuso una fórmula para ambos países, en la cual la enmienda argentina no aparecería oficialmente en los documentos de la Conferencia y sería disentida por la Asamblea General cuando ésta discutiera las conclusiones de la Conferencia de Estocolmo187. Así se hizo, y Suecia adoptó el punto de vista del Brasil sobre soberanía nacional en la aplicación de medidas de protección ambiental concernientes exclusivamente al territorio bajo su jurisdicción ${ }^{188}$. A pesar de repetidas objeciones por parte de la República Popular China ${ }^{189}$, el 16 de junio la Conferencia adoptó la Declaración sobre el Medio Ambiente que contenía 26 Principios, junto con otras resoluciones y, adicionalmente, preparó un Plan de Acción para el Medio Ambiente ${ }^{190}$.

${ }^{153}$ Jornal do Brasil, June 8, 1972, p. I

isf Jornal do Brasil, June 13, 1972, Ist caderno, p. 12.

${ }^{180}$ Jormal do Brasil, June 15, 1972, Ist caderno, p. 8; also, there was insistent cordemnation against the use of biological arms (principally bacteriological re: sources), just as there was against nuclear warfare.

1sojornal do Brasil, June 16, 1972, 1st caderno, p. 12; Jomal do Brasil, June 14, 1972, Ist caderno, p. 12 .

${ }_{187}$ Jornal do Brasil, June 16, 1972, 1st caderno, p. 12; the Argentine proposal had been presented in the form of an amendment to Principle 20 of the Declaration on the Environmental Project.

${ }^{188}$ Jormal do Brasil, June 14, 1972, 1st caderno, p. 12; Jornal do Brasil, June 18-19, 1972, Ist caderno, p. 16.

18sjornal do Brasil, June 17, 1972, 1st caderno, p. 8.

${ }^{100}$ For the text of these documents, cf. U.N., Report of the United Nations Conference on the Human Environment (Stockholm, June 5-6, 1972), document A/CONF.48/14/Rev. 1, 1973, pp. 1-77. 
Si bien la enmienda argentina no formó parte expresa del Principio 20 de la Declaración de 26 Principios, la Conferencia dejó abierta la cuestión de mecanismos de información y consulta previa en operaciones que, si se efectuaron en un país, podrían caúsar daño al medio ambiente más allá de sus fronteras: El tema surgió nuevamente en la XXVI Asamblea General cuando, en la apertura del debate general el 25 de septiembre de 1972, el Ministro Mario Gibson Barboza afirmó que la insistencia del Brasil sobre "él derecho soberano de cada estado para hacer el mejor uso de los rëcursos de sus territorios en beneficio de sú población no omite èl: reconocimiento de la responsabilidad para ejecutar sus planes de desarrollo sin riesgo y $\sin$ daño perceptible al medio ambiente de áreas vecinàs a su territorio" 191 .

Durante la xvIx Asamblea General, Brasil y Argentina llegaron a un acuerdo y presentaron un proyecto de resolución sobre el medio ambiente, en el cual acordaron recónocèr oficial y' públicamente los datos técnicos de los trabajos efectuados por un estado dentro de su jurisdicción nacional con el propósito de evitar un daño ambiental perceptible a los vecinos. Sin embargo, esa medida no debería interpretarse como el permiso para que cada estado demorara o impidiese programas o proyectos para la explotación y $\mathrm{de}$ sarrollo de recursos naturales en estados en cuyos territorios eran efectuados tales programas o proyectos ${ }^{192}$. El asi llamado proyecto brasileño-argentino sobre la materia fue aprobado integramente por la Xxux Asamblea General y se convirtió en la Resolución 2.995 por votación máxima; adoptando también las conclusiones de la Conferencia de Estocolmo y todos sus acuerdos ${ }^{193}$.

La importancia de proteger el medio ambiente en nuestro conti. nente puede ser ilustrada por un incidente relativamente reciente; en el cual se consideró la viabilidad de la onu y de la oza. Tan pronto se hizo público en marzo de 1975 que el tanque finlandés ENSKERI planeaba volcar cientos de barriles de desecho industria: (con un sustancial contenido de ársenico) en aguas internacionales del Atlántico Sur, Brasil, Uruguaỳ y Argentina enviaron pro. testas conjuntas al Ministro de Relaciones Exteriores finlandes; además Brasil, aparentemente apoyado por varios otros estados latinoamericanos, pidió que el Consejo Permanente de la OEA urgiese a Finlandia a no proceder con la descarga, que podría contaminar gran parte de la región del Atlántico Sur debido a las corrientes del Golfo. El Consejo Permanente fue citado para el 24 de mar-

${ }^{101}$ M.R.E., Documentos de Politica Exlerna, vol. vr, 1972, p. 200.

${ }^{202}$ M.R.E., Documento de Politica Externa, vol. v, 1972, pp. 204-205.

${ }^{15} A$ s. for the institutional arrangements; -it suggested creation of a Secretariat (headquartered in Nairobi), and of an Administrative Council for Environmental 'Programs, to which Brazil was elected for a two-year mandate (1973-1974); M.R.E., Documentos de Politica Externa, rol. Vir; 1973, pp; 257.259; 
zo. Brasil y otros países latinoamericanos acudieron al Secretario General de la onv, K. Waldheim, quien accedió à pedir al gobierno finlandés que no efectuase esta acción. En vista de la reacción latinoamericana, el Consejo de Estado finlandés decidió suspender sus planes, que reconoció eran contrarios a la Convención de Londres de 1972. sobre Descargas en el Océano y otros acuerdos internacionales apoyados por Finlandia. En vista de esto, la onU y la oEA no tuvieron que actuar, el gobierno del Brasil alabó la decisión finlandesa y los desechos que contenían arsénico fueron devueltos a territorio finlandés. En primer lugar, el éxito de este caso se debe a la conciencia que se ha desarrollado durante estos últimos tres años con respecto a la necesidad de proteger el medio ambiente (otros incidentes parecidos anteriores no tuvieron igual éxito) $y$; en segundo lugar, al hecho de que los países comprometidos tenían foros a nivel regional -el Secretariado General de la onU y el Consejo Permanente de la OEA- que podían ejercer presiones normativas o institucionales ${ }^{184}$.

Recientemente, en la Cuarta Sesión (Nairobi, 1976) del Consejo Administrạtivo de UNEP, Brasil, como miembro, reiteró los puntos básicos de su política de medio ambiente, que "no acepta la primacía de preocupaciones exclusivamente ecológicas sobre los esfuerzos para desarrollarse de los países en desarrollo"195. En esa sesión se establecio un grupo de especialistas sobre La Responsabilidad de los Estados por Daño Ambiental, incluyendo la representación del Brasili196.

Particularmente en el contexto latinoamericano, ya hay signos de preocupación a nivel internacional por la protección del medio ambiente. Por ejemplo, hubo un Seminario sobre Estilos de Desarrollo y Medio Ambiente en América Latina en noviembre de 1979

\footnotetext{
${ }^{19} \mathrm{R}$. B. Bilder, "The Settlement of Disputes in the Field of the International Law of the Environment", 144 Recueil des Cours de l'Academie de Droit International (1975), pp. 190-192. At that time, the Brazilian press announced that the Brazilian government only accepted the nomination -in that periodof the new Finnish ambassador to Brazil after being notified of Finland's decision to suspend its plans for dumping; ibid., p. 19l. - Cf., previously, "Relatorio da Delegação do Brasil a Conferéncia Internacional sobre a Poluição do Mar por Oleo (London, 1962)", in is Boletim da Sociedade Brasileira de Direito Internacional (1962) No 35/36, pp. 85-97. - For a summary of the main measures taken by the European countries in the national arena for protecting the environment, cf. A. A. Cançado Trindade, "Review of Ercman's European En: vironmental Law, Legal and Economic Appraisal”, 36 Cambridge Law Journal (1977), Cambridge University, pp. 406-407. 130-131.

${ }^{105}$ Relatorio do Ministerio das Relações Exteriores - 1976, M.R.E., 1979, pp.

129 Ibid., p. 131 - For a recent reevaluation of aspects of the general theory on the states' international responsibility, cf. A. A. Cançado Trindade, "A Determinação do Surgimento da Responsabilidade Internacional dos Estados", 4 Relações Internacionais - Brasilia (1979) 2. pp. 15.31.
} 
en Santiago, como parte de un proyecto del mismo nombre bajo el auspicio de cepal y unep. Como parte del proyecto, el Seminario intentó evaluar la interacción entre estilos de desarrollo prevalecientes en la región y problemas de utilización del medio ambiente y los recursos, y sugerir medidas para mejorar las condiciones ambientales y la utilización de recursos, incluyendo estilos alternativos de desarrollo ${ }^{197}$.

\section{Conferencia de las Naciones Unidas sobre el Derecho de los Tratados. (Viena, 1968-1969).}

Esta importante conferencia fue convocada luego de varios años de trabajos preparatorios sobre el Derecho de Tratados efectuados por la Comisión Legal de la oNU. La Conferencia se efectuó en Viena y fue dividida en dos sesiones: en la primera, en 1968, tomaron parte 103 estados y 110 en la segunda, en 196919s. Como observó un analista, la noción de "interés comunitario" presente en el trabajo preparatorio parece haber sido respetado por la Convención de Viena sobre el Derecho de los Tratados en su conjunto, haciendo así posible que el derecho establecido por la Convención no se aplicara exclusivamente sobre bases bilaterales; si de hecho ocurriese, los estados "pequeños y débiles"199 serían los principales beneficiarios.

Incluso durante los debates de la Asamblea General (IV Comité) desde 1963 a 1966, que precedieron a la Conferencia de Viena, se hizo claro que la mayoría de los internacionalistas de los países en desarrollo de Europa Oriental atribuyeran gran importancia al concepto de jus cogens ${ }^{200}$.

Brasil participó activamente en el trabajo de la Conferencia de Viena sobre la Ley de Tratados (1 $1^{\text {a }}$ y $2^{\text {a }}$ sesiones, 1968-1969). Se pueden destacar algunas intervenciones brasileñas. El principio de no retroactividad de la Convención (Artículo 4) resultó de una idea propuesta por las delegaciones de Brasil, Suecia y otros paí$\operatorname{ses}^{201}$. Las cláusulas finales de la Convención (Artículos 81 a 85)

${ }^{107}$ Cf. report in U.N., document E/GEPAL/PROY.2/G.1, January 4, 1980, pp. 1-60.

105. M. Sinclair, "Vienna Conference on the Law of "Ireaties", 19 International and Comparative Law Quarterly" (1970), pp. 47-69.

${ }^{188} \mathrm{~S}$. Rosenne, Bilateralism and Community Interest in the Codified Law of Treaties", Transnational Law in a Changing Society - Essays in Honour of Ph. C. Jessup (ed. W. Friedmann, L. Henkin, O. Lissitzyn), N. Y./London, Colum. bia University Press, 1972, pp. 226-227, and cf. pp. 212-219.

${ }^{200}$ I. M. Sinclair, op. cit. supva No 198, pp. 66-69; I. M. Sinclair, The Vienna Convention on the Law of Treaties, Manchester, University Press/Oceana, 1973, pp. 124-129, and cf. pp. 129-131; cf. also, P. Reuter, La Convention de Vienna sur le droit des traités, Paris, A. Colin, 1970, pp. 86-87. For the history of the concept, cf. Jerzy Sztucki, Jus Cogens and the Vienna Convention on the Law of Treaties - A Critical Appraisal, Vienna, Springer-Verlag, 1974, pp. 6-11 and $97-108$.

${ }^{301}$ G. E. do Nascimento e Silva, Conferéncia de Vienna..., op. cit. supra NQ 55, pp. 62-63. 
estaban basadas en gran parte en una propuesta anglo-brasileña ${ }^{202}$. Otra área importante fue la relacionada con las reservaciones a la Convención. Otra vez prevaleció una propuesta anglo-brasileña. De acuerdo al jefe d.e la delegación brasileña, embajador Nascimento e Silva, "la conferencia terminó adoptando la fórmula anglo-brasileña que, en último análisis, refiere la solución a los artículos de la Convención 19 al 23, esto es, que las reservaciones deben ser compatibles con los objetivos y propósitos de la Convención. En otras palabras, las únicas reservaciones admisibles para la Convención del Derecho de Ios Tratados son aquellas que no tocan lo fundamental, con el riesgo de tener la oposición de otras partes y ser llevadas a la decisión de la Carta Internacional de Justicia en el caso de los Artículos 53 a $65^{203}$.

Si bien la Convención de Viena hasta ahora no ha entrado en vigor, su simple existencia y su éxito representan una recompensa por los grandes esfuerzos intelectuales de Ios miembros de la Comisión Legal Internacional de la oNu y un punto significativo en el conflictivo proceso histórico de la codificación y desarrollo progresivo del derecho internacional ${ }^{204}$.

\section{Conferencias de Población de la onu (1974) y Habitat (1976)}

Se puede decir que, en políticas demográficas, los países miembros de la onU están divididos grosso modo entre aquellos que favorecen la acción internacional en el control de natalidad y aquelios que dan más peso al así llamado interés nacional.

Sobre este tema, la posición oficial del Brasil ha sido no restringir el crecimiento demográfico mientras la tasa de crecimiento económico y empleo están en una relación suficientemente alta. En la XxIv Asamblea General (III Comité) en 1964, la delegación brasileña se mostró "contraria a un ítem que favorecía políticas pobiacionales destinadas a propagar el control de la natalidad"205.

El impasse entre los movimientos divergentes se hizo sentir en la Conferencia sobre Población de la ONU (Bucarest, agosto 1974). Para dar credibilidad a este punto de vista de que las materias de-

sarIbid., pp. 86-87.

sold., P. 54; and on the incorporation by the Vienna Convention of the flexible pan-American doctrine in reservations (according to such a tendency in international practice during the last three decades), cf. I. M. Sinclair, op. cit. supra No 198, pp. 47-69 (and cf. articles 19-20 of the Vienna Convention).

${ }^{20+I n}$ this regard, I. M. Sinclair, The Vienna Convention..., op. cit. supra No 200, pp. 144-145; cf. documents of the Conference in Uniled Nations Conference on the Law of Treaties, Official Records (1968-1969), vols. I and II, do. cuments A/CONF.39/11/Add.1 and 2; cf. also, the valuable commentaries of the U.N. International Law Commision, in International Law Commission Reports (1966), pp. 10ss.

${ }^{205}$ Rélatorio do Ministerio das Relaçóes Exteriores - 1969, M.R.E., 1973, p. 82. 
mográficas caen bajo el dominio reservado y la exclusiva jurisdicción nacional, Brasil consideró confrontar los ataques hechos por la Comisión de Población y el Fondo para Actividades Demográficaś, ambos de la ONU206.

Menos de dos años después, Brasil tomó parte en la 'Conferencia de la ONU sobre Asentamientos Humanos: HABITAT (Vancouver, mayo-junio 1976). La Conferencia pretendía reconciliar un intercambio de experiencias nacionales al tratar la materia y también avanzar una "revisión crítica de políticas y programas para asentamientos humanos, tanto en los niveles nacionales como internacionaIes"207. De acuerdo con el informe anual de Itamaraty, la delegación brasileña fue cuidadosa en esa ocasión para "evitar el establecimiento de patrones universales que no tomen en cuenta la diversidad socio-económica de cada país" y, en este sentido, "las metas brasileñas fueron plenamente alcanzadas" 208 .

\section{CONSIDERAGiones finales: Brasil y el MUltilaterismo}

Al finalizar este estudio, se pueden mostrar otras posiciones tomadas por Brasil dentro de los órganos internos principales de la ONU (y de la OEA) y en las conferencias multilaterales bajo auspicios de la onU (supra) están las posiciones adoptadas por Brasil en las diversas agencias especializadas de la onu donde éste mantiene representación.

Se pueden destacar varios aspectos, entre ellos las Convenciones Internacionales del Trabajo (bajo supervisión de la orT), ratificado por Brasil ${ }^{209}$, los acuerdos trilaterales entre Brasil, los Estados Unidos y la raEa (Agencia Internacional de Energía Atómica) (1967-1968) ${ }^{210}$ y Brasil-Alemania Federal-IAEA (1975-1976) ${ }^{211}$ para aplicación de acuerdos de salvaguardias nucleares, el intento de Brasil de alinearse con los objetivos de la UNESCO en un nivel multilateral212, y la posición del Brasil en agencias tales como la FAO, oMs, entre otras ${ }^{213}$.

Otra área que requiere estudio separado en el nivel de relaciones entre estados, es el compromiso del Brasil en acuerdos multila-

${ }^{200}$ M.R.E., Documentos de Politica Externa, vol. vir, 1973, p. 261.

${ }^{207}$ Relatorio do Ministerio das Relaçöes Exteriores - 1976, M.R.E., 1979, p. 130. Ibid., p. 130.

${ }^{200}$ W. D. Giglio, orx $e$ Convengões Internacionais do Trabalho Ratificadas pelo Brasil, Ist ed., São Paulo, Sug. Liter., 1973, pp. 63-404; and cf. also, e.g., Re. latorio do Ministerio das Relą̧б̄es Exteriores - I970, M.R.E., 1973, p. 103.

${ }^{210}$ Ministerio das Relações Exteriores/D.A.I, Coleção de Atos Internacionais, No 673 , pp. 3-25.

melatorio do Ministerio das Relações Exteriores - 1976, M.R.E., 1979, p. 134. gacf., in this regard, e.g., M.R.E., Resenha de Politica Exterior do Brasil, $N^{\circ}$ 19, October-December 1978, pp. 81-85.

${ }^{213}$ On Brazil in these three agencies, cf. e.g., Relatorio do M.R.E. $-1970, \mathrm{pp}$. 100-104; Relatorio do M.R.E. - 1976, pp. 133-134 and 138-139. 
terales de diversa naturaleza y propósito. Esto puede ser ilustrado por el Tratado del Acuerdo de la Cuenca del Plata, ratificado por Brasil el 30 de julio de 1969214; Ia adhesión del Brasil al Tratado de la Antártica (1959) en mayo de 1975215; y más recientemente el Tratado de Cooperación Amazónica (1978) ${ }^{216}$; entre otros.

Otra área menos examinada, pero que merece atención, es la consideración por parte del Congreso Nacional del Brasil de temas de pölítica exterior brasileña al nivel multilateral217. Entre los innumerables temas considerados destacan varios, p. ej., la intervención de la osa en República Dominicana (1965), que aparece en los Anales del Senado Federal218, como también en los de la Cámara de Diputados 219; la Operación Panamericana (O.P.A.) a principios de los $60^{220}$; el trabajo de la UNCTAD221 y las organizaciones regionales (internacionales) ${ }^{222}$ y diversos items debatidos en la Asamblea

${ }^{2}{ }_{\mathrm{M}}$,R.E., Coleção de Atos Internacionais, No 633, pp. 3-11; and cf. João Hermes Pereira de Araujo, "Bacia do Prata", Valores e Rutmos do Mundo Ocidental (II Painel de Assuntos Internacionais da Comissão de Relações Exteriores da - Caraara dos Deputados), Brasilia, 1978, pp. 255-265.

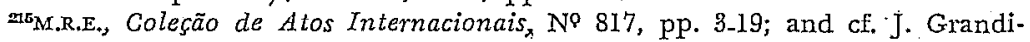
no Rodas, "Brasil Adere ao Tratado da Antartida", 71 Revista da Faculdade de Direito da usP (1976), pp. 151-161.

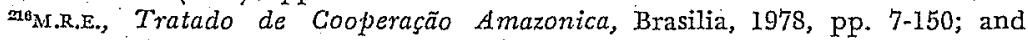
cf. Rubens Ricupero, "Tratado de Cooperação Amazonica", 5 Relaçóes Intermacionais - Brasilia (1980) pp. 3.7; L. Marinas Otero, "El Tratado de Cooperación Amazónica", 166 Revista de Politica Internacional - Madrid (1979) pp. 63-71. And, for a comparative study between the Treaty of the La Plata Basin and the Amazon Pact, cf. J. E. Greno Velasco, "Pacto Amazónico Y Tratado de la Cuenca del Plata: Analogías y Diferencias", 165 Revista de Politica Internacional - Madrid (1979) pp. 75-92.

${ }^{21}$ Here, we point out the data survey on the (Brazilian) Federal Senate and Chamber of Deputies, carried out under my supervision by my former students at the University of Brasilia Department of Political Science and International Relations - Marta Regina Rodrigues da Cunha, Eliane Vieira Martins, Wanja Campos de Nobrega, Norma da Silva Venancio Pires, and Ana Beatriz d'Azevedo Macieira-, as fellows of the Memoria Politica Nacional project in 1979 , under an agreement between the University of Brasilia and the Chamber of Deputies.

${ }^{218}$ Anais do Senado, May 1965, sessions 39.50, vol. I, pp. 82, 129, 196 and 336; ibid., September 1965, sessions 143-145, pp. 93-94.

${ }^{210}$ Anais da Camara dos Deputados, September 17-28, 1965, vol. 24, pp. 129 131; ibid., September 2-13, 1965, vol. 25, pp. 196-197; and cE. also, ibid., May 12-17, 1965, vol. 8, pp. 703-708.

$=0$ Anais do Senado, July 17-29, 1960, sessions 91-106.

Anais da Camara dos Deputados, March 10-24, 1964, vol. I, pp. 712-713 (I UNGTAD); Anais do Senado, February 1968, sessions 13-27, pp. 220-223 (II UNCTAD) ; ibid., November 1968, sessions 276-298, vol. II, pp. 488-498 (II UNCTAD).

202 Anais do Senado, November 1968, sessions 276-298, vol. Ir, pp. 307-314 (EEC and OECD). A most frequent debated subject was Cuba's position among the American countries at the beginning of the 1960s: Anais da Camara dos Depu. tados, April 19-26, 1.961, vol. Iv, pp. 163 and 316; ibid., February 2-13, 1962, vol. I, pp. 437.444; ibid., August 17 to September 12, 1962, vol, xrx, p. 725; cf. also 
General lecho del mar228 y desarme ${ }^{224}$, censura del régimen de apartheid de Sudáfrica ${ }^{225}$, el aumento en el número de miembros del Ecosoc y Consejo de Seguridad ${ }^{220}$, entre otros ${ }^{227}$.

Una de las más marcadas características de la así llamada sociedad internacional es probablemente la descentralización de su estructura, contraria al orden interno o nacional, que carece de órganos legislativos estrictamente supranacionales y está fragmentada en diversas unidades nacionales o nacionalistas ${ }^{228}$. Las peculiaridades de la así llamada sociedad internacional son acentuadas, por ejemplo, por las dificultades en aplicar medidas coercitivas al nivel interna. ciona ${ }^{229}$. Sería riesgoso, sin embargo, abocar que una estructura tal pueda ser un factor permanente o inmutable de la así llamada sociedad internacional. En este respecto, ya en 1926 Politis advirtió que la evolución de uno u otro grupo social (p. ej. relaciones entre tribus, clanes, familias, ciudades y naciones) opera "por una serie de etapas sucesivas y reformas superimpuestas" y así, no se

ibid., Novenaber 23 to December 7, 1961, vols. 31:33, pp. 106, 185, 191-192, 150 and 315 (resumption of diplomatic relations ivith the USSR)

$=$ Anais do Senado, February. 1968, sessions 13-27, p. 227.

$=$ Anais do Senado, February 1960, sessions 9-24, pp. 463-464.

mIbid., p. 465 .

2201 Ibid., p. 465.

${ }_{20 T E}$.g., the cases of Korea, Algeria, and Hungary, among several others; cf. ibid, pp. 464-465. - In addition, see the genernl impressions collected by parliamentarians at U.N. General Assembly sessions; cl., in this regard, e.g., Anais do Senado, November 1968, sessions 276-298, vol. II, p. 517 (the Czechoslovakia question, the Middle East crisis, the Namibia problem, dealt with at the Xxir General Assembly); Nelson Carneiro, Notas de um Observador Parlamentar a xxr Assembleia Geral da onv, Brasilia, ed. Senado Federal, 1971, pp. 5-26, esp. pp. 9-15, 18 and 20.21 (Brazil and admission of the People's Republic of Chna to the U.N.). Another aspect, virtually unexplored, is that of Brazilian practice on international claims; cf., in this regard, research by A. A. Cançado 'Trindade, "O Contencioso Diplomático e os Recursos de Direito Interno", 66 Revista de Informação Legislativa do Senado Federal (1980) Parte IV: "A Pratica do Brasil"), pp. 153-174; and on procedural aspects of international claims, cf. A. A. Cançado Trindade, The Rule of Exhaustion of Local R'emedies in International Law, Cambridge, Cambridge University Press, 1982 (in print).

${ }^{208} \mathrm{~A}$. A. Cançado Trindade, "La methode comparative en droit international, une perspective europeenne", 55 Revue de droit international de sciences diplomatiques et politiques (1977), pp. 273-287; A. A. Cançado Trindade, "Reflexões sobre o Metodo Comparado no Direito Internacional", 151 Arquivos do Ministerio da Justiça (1979), pp. 81-92. However, it would not be viable or even feasible to attempt to apply the measure of the domestic Iaw of subordination to the international legal order of coordination; A. A. Cançado Trindade, Considerações acerca do Relacionamento.... op. cit. supra No 154, pp. 13-14.

${ }^{229}$ As attested to by the League of Nations attempt to apply economic sanctions on Italy in 1935 (cf. F. P. Walters, A History of the League of Nations, Oxford, University Press, 1969, pp. 623-691), and the U.N.'s application of sanctions on Rhodesia beginning in 1965 (cf. L. T. Kapungu, The United Nations and Economic Sanctions against Rhodesia, Toronto/London, Lexington Books, 1973, pp. 39-141). 
puede ignorar la posibilidad de que nuestro siglo esté experimentando un pasaje imperceptible y gradual desde relaciones puramente inter-estado (a través de canales gubernamentales de los estados) a las mismas relaciones internacionales ${ }^{230}$.

En el curso de este proceso histórico, las últimas tres décadas han seguido la evolución de un fenómeno muy importante, aquel del auge y expansión de las organizaciones internacionales. Su desempeño ha causado considerable impacto en la teoría y práctica de la legislación y relaciones internacionales. La proliferación de las organizaciones internacionales que operan en los más diversos sectores trae un considerable aumento en sus poderes regulatorios, variando de una organización a otra.

En el proceso de toma de decisiones al nivel internacional, el desempeño de las organizaciones internacionales es normalmente externalizado a través de resoluciones de naturaleza, contenido y efectos variables ${ }^{231}$ y Ios estados principales contribuyeron decisivamente a su adopción. En algunos casos es incluso posible discernir una intención de parte de un organismo internacional dado para formular proposiciones o principios existentes de derecho internacional; esto es ilustrado por las declaraciones de la Asamblea General de la ONU - precedidà de debates en los cuales participó Brasilacerca de la soberanía permanente sobre los recursos naturales (de 1962 en adelante) o sobre la prohibición del uso de armas nucleares y termonucleares (1961). El consenso, como un nuevo proceso de toma de decisiones y métodos de extender el derecho internacional a nuevas áreas, es aparente en las declaraciones de la Asamblea General sobre principios legales que gobiernan la exploración y el uso del espacio por los estados (1961 y 1963). Las resoluciones declaratorias, aun cuando contenían acuerdos generales, llevaban una insuficiencia básica en la así llamada socieclad internacional, en la cual dudas, inestabilidad e incluso contradicciones con respecto a las reglas que gobiernan o debieran gobernar la conclucta de las relaciones internacionales surgen de la misma ausencia de órganos legislativos permanentes y de la naturaleza no institucionalizada del proceso en el cual es creacia la ley internacional ${ }^{232}$.

La técnica de consenso en la diplomacia multilateral contemporánea, que aparece como uno de los fenómenos más significativos y modernos de la multilateralización y "diplomacia parlamenta-

${ }^{230} \mathrm{~N}$. Politis, The New Aspects of International Law, Washington, Carnegie Endowment for International Peace, 1928, p. 24.

${ }^{21} \mathrm{Cf}$. A. A. Cançado Trindade, Principios do Direito Internacional Contemporaneo, op. cit. supra No 126, pp. 187-221 and bibliography. The means whereby international organizations adopt resolutions also vary (e.g., simple and qualified majority, weighted vote, consensus, unanimity).

${ }^{203} J$. Castaneda, Legal Effects of United Nations Resolutions, N. Y., Columbia University Press, 1969, pp. 165.196, and cf. pp. 22-116, for resolutions of a mandatory nature. 
ria"'233, se ha demostrado como particularmente efectiva en su propósito de evitar confrontaciones ${ }^{234}$. Más aún, en vista de los grupos y bloques regionales que a menudo defienden conflictivos intereses y puntos de vista, ha estimulado posiciones más flexibles de parte de los estados, basadas en la premisa de que argumentos bien negociados son siempre preferibles a pronunciamientos unilaterales a nivel internacional:

De este modo el uso contemporáneo del consenso es comprensible en tales amplios foros multilaterales, que a menudo tienen 140 miembros, como en la UNCTAD, (que no pueden funcionar bien en medio de una simple y constante confrontación política entre los países más y menos desarrollados) y la actual III Conferencia del Derecho del Mar, entre otras ${ }^{235}$. Hloy en día, se ve una conciencia general de que la supuesta "autosuficiencia" del estado territorial podría sólo haber florecido durante una exa que se creía a sí misma "políticamente segura" e invulnerable en términos globales ${ }^{236}$, lo que ya no es el caso hoy en día.

Incluso en el nivel de puras relaciones entre estados, ningún estado conduce su propia polftica exterior $a b$ initio; al seleccionar un curso para seguir hay siempre un elemento de elección entre alternativas dictadas en gran parte por las circunstancias. Los mismos problemas por resolver no son siempre creados por un estado determinado y a menudo son impuestos "desde el exterior" por la complejidad de las relaciones internacionales. Aún más, los mismos medios para resolver los problemas a menudo representan un consenso obtenido por un grupo de estados de desigual poder ${ }^{237}$. De esta manera, en la era del sistema de seguridad colectiva de la oNu, con la multiplicación de nuevos estados independientes, muchos estados han identificado el multilateralismo en el proceso de toma de decisiones a nivel internacional; un factor que hasta un

${ }^{2 a} A s$ well stated by $\mathrm{Ph}$. C. Jessup, "Parliamentary Diplomacy: An Examination of the Legal Quality of the Rules of Procedure of Organs of the United Nations", 89 Recueil des Cours de l'Academie de Droit International (1956), pp. 185-319; and cf., more recently, e.g., F. Przetacznik, "Les conferences internationales comme une de; formes de la diplomatic contemporaine", 5l Revue de droit internationale de sciences diplomatiques et politiques (1973), pp. 46-61 and 104-117.

Erik Suy, "The Meaning of Consensus in Multilateral Diplomacy", Declarations on Principles, $A$ Quest for Universal Peacc - Liber Amicorum Discipulorumque B. V. A. Roling, Leyden, Sijthoff, 1977, pp. 260-261 and 272.

${ }^{25}$ Such as the rcosoc and in the preparatory work of the U.N. World Conference on Population (1979, and debates on procedural rules of the U.N. Commission on Population).

${ }^{230}$ Maarten Bos, "Dominant Interests in International Law", 21 Revista Española de Derecho Internacional (1968), p. 234.

arF. S. Northedge and M. J. Grieve, A Hundred Years of International R'elations, London, Duckworth, 1971, pp. 344-345; A. A. Cançado Trindade, "Direito e Relaçóes Internacionais...", op. cit. supra No 35, p. 99. 
cierto grado compensa por sus desigualdades de poder en la escena. internacional y que modula patrones de conducta de los estados al nivel internacional 238 .

Es verdad que en muchas ocasiones Brasil ha optado por conducir sus relaciones internacionales en un nivel bilaterale39 con ciertos países e incluso en virtud de la naturaleza de los temas. Sin embargo, Brasil ha permanecido consciente de la significancia y relevancia de los foros multilaterales de negociación. Hace una década, el entonces canciller brasileño advirtió que la "multilateralización es actualmente una tendencia irreversible... y que las $\mathrm{Na}$ ciones Unidas constituyen la clave, el mecanismo diplomático central de sus formas multilaterales de vida juntos. La verificación objetiva de este aspecto de la realidad internacional de nuestro tiempo condiciona la actitud general del Brasil hacia la onv y la lleva a participar activamente en todos los consejos y agencias especializadas de Ia ONU"240.

Particularmente desde 1965 en adelante (II UNCTAD), Brasil comenzó a hacer público su apoyo a foros multilaterales de negociación, como un medio para neutralizar o reducir el considerable poder de coerción de los superpoderes y de los grandes poderes en las relaciones internacionales. Así, mostrando su voto de confianza en los mecanismos de la onU, innumerables veces representantes de Itamaraty se opusieron al retorno del concepto de zonas de influencia. Defendieron a las organizaciones internacionales como la única esperanza de los países menos poderosos para participar efectivamente en la dirección de problemas globales que afectan a todas las naciones, como una alternativa válida al uso de presiones políticoeconómicas que pueden desencadenar regresiones históricas que dividen el mundo en áreas de influencia ${ }^{241}$.

${ }^{238} \mathrm{Cf}$, e.g., the reflections of E. Hambro, "Some Notes on Parliamentary Diplomacy", Transnational Law in a Changing Society - Essay's in Honour of Ph. C. Jessup (ed. W. Friedmann, L. Henkin, O. Lissitzyn), N. Y., Columbia University Press, 1972, pp. 280-297.

${ }^{230}$ Th. E. Skidmore, "O Papel do Brasil em Face do Sistema Internacional: Implicações com Relaçăo a Política Norte-Americana”, in R. Roett (org.), $O$ Brasil na Decada de 70, Rio de Janeiro, Zahar, 1978, p. 41; Ghristopher Roper, "Inter-American Relationships", The World Today - London (November 1971) pp. 486-494; Celso Lafer, "Política Exterior Brasileira: Balanço e Perspectivas", 4 Relações Internacionais - Brasillia (1979), pp. 52.53 (Brazil's preference for bilateral relations that are "seen as substantive").

${ }^{210}$ M.R.E., Documentos de Politica Externa, vol. rv, 1969-1970, p. 190. Cf. also, in general, Afonso Arinos de Melo Franco, " $A$ onv $e$ a Politica Exterior do Brasil”, 20 Digesto Económico (1962), No 168, pp. 129-136; and for a quantitative analysis of statistical data on Brazil's voting record in the U.N., cf. W. A. Selcher, Brasil's Multilateral Relations - Between First and Third Worlds, Bouldcr/ Col., Westview, 1978, chap. 6, pp. I75-212.

"i1 José de Magaihâes Pinto, op. cit. supra No 29, pp. 65 and 71 ; Carlos Calero Rodrigues, op. cit. supra No 136, p. 43; Jorge de Carvalho e Silva, op. cit. supra No 96, p. I8I; L. A. P. Souto Maior, "A Política Externa do Brasil", 42 
Ya han sido revisadas algunas de las posiciones del Brasil en el nivel multilateral. Hoy se puede decir que casi todos los' temas debatidos en los plenarios de la onu afectan no sólo la así llamada sociedad internacional como un todo sino que, directa o indirectamente, a cada estado en particular que intente usar los foros diplomáticos multilaterales para tratar y promover ciertas cuestiones que son favorables a sus intereses y necesidades. Un ex Ministro de Relaciones Exteriores identificó los poderes pequeños e intermedios como los más constantes "aliados" de Brasil en el sistema de la onv y añadió que: "el peso político específico del Brasil sólo le permite participar activamente en discusiones y negociaciones de problemas de este tipo (seguridad colectiva internacional) cuando tales discusiones y negociaciones tienen lugar en las Naciones Unidas. Los pequeños poderes tales como el Brasil deben intentar influir el curso de los acuerdos sobre paz y seguridad vía los mecanismos diplomáticos multilaterales de la oNu'242. Por eso, no es sorprendente que el Brasil haya defendido el proyecto del fortalecimiento de la seguridad colectiva internacional (supra).

El moderno fenómeno de la multilateralización corrobora la tesis de que el clásico concepto de soberanía, concebido originalmente como una expresión del poder interno del estado in abstracto ${ }^{243}$

Revista Brasileira de Estudos Poltticos (1976), pp. 195-196; Mario Gibson Baxboza, "A Politica Exterior do Brasil", 30 Digesto Economico (1973) No 234, pp. 167-175 (politics of deténte and revitalization of U.N. mechanisms); Azeredo da Silveira, "A Polftica Exterior do Brasil", 34 Digesto Economico (1976) No 252, P. 28 ("natural convergences" of superpowers, intermediate countries, and weaker countries, superceding long-standing alignments); Azeredo da Silveira, "As Relações Diplomaticas do Brasil com a America Latina", 32 Digesto Economico (1975) No 245; $\mathrm{P}_{\mathrm{n}} 4$ (the influence of detente on the course of inter-American relations); A. F. "Azeredo da Silveira, "A Política Externa e a Ação do Itamaraty", Valores e Rumos do Mcndo Ocidental (II Painel de Assuntos Internacionais da Comissão de Relações Exteriores da Camara dos Deputados), Brasilia, 1978, p. 497 ("multiplicity of political relationships") ; R. E. Saraiva Guerreiro, "Pontos de Conflito na Comunidade das Nações", Valores e Rumos" do Mundo Ocidental, Cam. Dep./C.R.E., Brasilia, I978, p. 375 (Current predominance of "politics of relaxation" of international tensions); L. A. de Souto Maior, "O Policentrismo e Novos Sistemas de Aliança", A Nova Ordem Mundial (r Painel de Assuntos Internacionais da Comissão de Relaçőes Exteriores da Camara dos Deputados), 2nd ed., Brasilia, 1977, pp. 63-64 (reduction of superporver hegemony) .

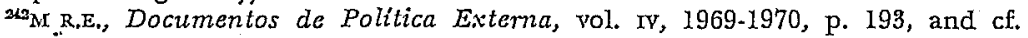
pp. 190̈-193; Mario Gibson Barboza, "As Naçóes Unidas e o Brasil", 27 Boletim da Sociedade Brasileira de Direito Internacional (1971), pp. 74-75.

${ }^{2}$ Clovis Bevilaqua, Direito Publico Internacional, Rio de Janeiro, Livr. Francisco Alves, 1911, pp. 66-67, 72-73 and 78; J. L. Brierly, "Regles genéralés de droit de la paix", 58 Recueil des Cours de l'Academie de Droit International (1936), pD. 24-25; E. N. Van Kleffens, "Sovereignty in International Law", 82 Recueil des Cours de l'Academic de Droil International (1954), pp. 5-83 and 107-130. - As is known, in the era of historical formation of the national states, the concept reflected a reaction against papal and imperial authority and was 
prueba ser inadecuado cuando cambia desde el ámbito interno a aquel de las relaciones internacionales, en el cual se acerca más al sentido de independencia que a uno de supremacía, dado el principio de la igualdad jurídica de los estados ${ }^{244}$. Aún más, en las relaciones multilaterales interestatales y bilaterales, la soberanía está sujeta a limitaciones que se derivan de los imperativos de la actual impasse nuclear. Se imponen otras limitaciones a través de la creación y de las acciones de organizaciones internacionales y de la supuesta "institucionalización" gradual de relaciones en las cuales la organización actúa como parte. Este es el fenómeno al que Arangio-Ruiz llamó el vuelco histórico del droit relationnel al droit organizationne $l^{245}$ o, en el lenguaje de Boutros-Ghali, el vuelco de la así llamada sociedad internacional de la fase contractual a la "institucional"246.

Es sabido que hoy en día, paralelamente a las puras relaciones interestatales, hay relaciones entre organizaciones internacionales ${ }^{r}$ sus estados miembros, y hay incluso relaciones interorganizaciona$\mathrm{Ies}^{247}$. En las relaciones entre las organizaciones internacionales y sus estados miembros, dada la naturaleza de ellas, el concepto del dominio reservado de los estados no ha sido tan decisivo y absoluto como en las relaciones interestatales, como lo prueba la práctica de Ios órganos internacionales ${ }^{248}$. Así, en relación a aquellas organizaciones, por ejemplo, los estados ya no poseen los monopolios de ser miembros (p. ej. Organización Mundial de la Salud, Unión Postal Universal) y de la representación (p. ej. sistema tripartita de la OIT); algunas agencias especializadas de la ONU poseen ciertos

used to consolidate the work of national unification and the state's internal structure (as a supreme power).

${ }^{\text {su }}$ Clive Parry, "The Function of Law in the International Community", Manual of Public Internalional Law (ed. M. Sorensen), London, MacMillan, 1968, p. 13; N. Politis, "Le probleme des limitations de la souverainete et la theorie de l'abus des droits dans les rapports internationaux", 6 Recueil des Cours de l'Academie de Droit International (1925), pp. 5-23; F. S. Northedge and $M$. J. Grieve, A Hundred Years..., op. cit. supra No 237, pp. 342-343.

${ }^{24} G_{i}$. Arangio-Ruiz, "The Normative Role of the General Assembly of the United Nations and the Declaration of Principles of Friendly Relations", 137 Recueil des Cours de l'Academie de Droit International (1972), pp. 665, 684685 and 713 .

3. Boutros-Ghali, "Le principe d'egalité des Etats et les orgasations internationales", 100 Recueil des Cours de l'Academie de Droit International (1960) pp. 11 and 14-15.

${ }^{24}$ Through the exchange of observers, liaison mission (joint committees or: "commissions de collaboration") establishment of a common organ and conclusion of agreements among them; R. J. Dupuy, "Le droit des relations entre les organisations internationales", 100 Recueil des Cours de l'Academie de Droit International (1960), pp. 461-584.

${ }^{\text {sss }}$ For a detailed study, cf. A. A. Cançado Trindade, $O$ Estado e as Relações Internacionais: $O$ Dominio Reservado dos Estados..., op. cit supra No 125, pp. 13-43, and documentation. 
mecanismos internos de control (p. ej. sistemas de quejas) y de poder "cuasi legislativo" (p. ej. para la adopción de convenciones) y, en los casos extremos en que las organizaciones internacionales aplican medidas coercitivas $\rightarrow$ no sin dificultacles ( $p$. ej. apartheid y colonialismo) - Ios estados responsables dejan de tener el monopolio de la última palabra ${ }^{249}$. Como ya se ha mostrado, los organismos internacionales, particularmente aquellos de las Naciones Unidas, han determinado en la práctica su propia competencia en interpretar partes de la Carta de la onU que son aplicables al desempeño diario de sus tareas específicas ${ }^{250}$. Tal vez la tesis de Eustathiades es verdadera: en las últimas décadas los estados se han sometido a consideraciones de legalidad y legitimidad para ejercer su política exterior ${ }^{251}$. Es indudable que todos los estados hacen un esfuerzo para conducir su política exterior de acuerdo con sus obligaciones internacionales para no transformarse en blanco de condenaciones a través de resoluciones de las organizaciones internacionales.

Hoy día los estados luchan dentro de las organizaciones internacionales por la soberanía permanente sobre los recursos naturales y por el establecimiento de un nuevo orden económico internacional. De estos desarrollos recientes surgen aparentes paradojas: por ejemplo, en el derecho del mar, la mayoría de los estados costeros reclaman derechos dentro de su zona económica exclusiva y al mismo tiempo defienden un régimen internacional para los fondos marinos más allá de los límites de su jurisdicción nacional (adviértase el nuevo concepto de "herencia común de la humanidad" y su afinidad con la noción de "res communis" en el derecho espacial contemporáneo). Igualmente, la mayoria de los estados insisten en el establecimiento de un nuevo orden económico internacional, en tanto que, al mismo tiempo y en aparente contradicción, argumentan en favor de la permanente soberanía de cada estado sobre sus recursos naturales ${ }^{252}$.

Las paradojas son más aparentes que reales. Para empezar, los actuales acontecimientos están relacionados con el fenómeno de la descolonización, cle donde surge la necesidad de hacer valer la soberanía permanente para un contenido económico y no ya únicamente político. Aún más, el orden internacional recién se ha equi-

${ }^{21} \mathrm{Cf}$. A. H. Zarb, "Souverainete et institutions specialisées des Nations Unies", La souverainete au xxe siécle, Paris, Libr. Armand Colin, 1971, chap. vin, pp. $236-277$.

${ }^{30} \mathrm{Cf}$. A. A. Cançado Trindade, $O$ Estado $e$ as Relaçóes Internacionais: $O$ Dominio Reservado..., op. cit., supra No 125, pp. 13-43.

${ }^{251} \mathrm{Cf}$. C. Th. Eustathiades, "Evolution des Rapports entre le droit international et la politique etrangère", Melanges offerts a Henri Rolin, Paris, Pedone, 1964, pp. 1-13 "(excerpt).

${ }^{x} \mathrm{Ph}$. de Seynes, "United Nations Study of the Multinational Corporations", 44 Nordisk Tidsskrift for intemational Ret (1974-1975), pp. 9.16. 
parado con la evolución de las actividades comerciales transnacionales y el fenómeno de la internacionalización de la producción. La afirmación de su soberanía permanente sobre los recursos naturales por parte de los estados en los foros multilaterales -y Brasil no es excepción- se toma como un "preámbulo" al derecho internacional contemporáneo, pero no en el sentido de la supremacía del estado como en el clásico concepto de soberanía.

Los estados, particularmente los más débiles, están totalmente conscientes de su creciente insuficiencia y vulnerabilidad, e insisten acerca de la así llamada autodependencia colectiva, destinada al establecimiento de un nuevo orden económico internacional más equitativo. Así, el nuevo concepto de soberanía permanente es la negación misma de la dependencia económica, por aplicación del principio básico de "desigualdad compensatoria"253. Parece, por consiguiente, fundamentalmente diferente del concepto tradicional y exclusivista de la soberanía del estado. Y, en una forma decisiva, las organizaciones internacionales han contribuido a estas nuevas posiciones que están surgiendo hoy en día, más particularmente las Naciones Unidas, como una organización internacional con una vocación universal par excellence.

${ }^{2}$ Cf. e.g., G. Feuer, "Les Nations Unies et le nouvel ordre economique international (1974-1976)", 104 Journal du droit international (Clunet) (1977), pp. 607 and 617-618; P. M. Martin, "Le nouvel ordre economique internationaï", 80 Reoue générale de droit international publique (1976), pp. 508, 519, and 535 . 